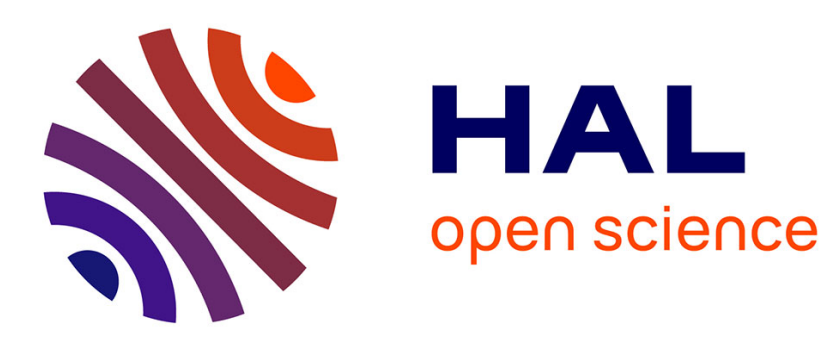

\title{
Base free oxidation of 1,6-hexanediol to adipic acid over supported noble metal mono- and bimetallic catalysts
}

\author{
M. Mounguengui-Diallo, F. Vermersch, N. Perret, C. Pinel, M. Besson
}

\section{To cite this version:}

M. Mounguengui-Diallo, F. Vermersch, N. Perret, C. Pinel, M. Besson. Base free oxidation of 1,6hexanediol to adipic acid over supported noble metal mono- and bimetallic catalysts. Applied Catalysis A : General, 2018, 551, pp.88-97. 10.1016/j.apcata.2017.12.005 . hal-01721923

\section{HAL Id: hal-01721923 \\ https://hal.science/hal-01721923}

Submitted on 17 May 2020

HAL is a multi-disciplinary open access archive for the deposit and dissemination of scientific research documents, whether they are published or not. The documents may come from teaching and research institutions in France or abroad, or from public or private research centers.
L'archive ouverte pluridisciplinaire HAL, est destinée au dépôt et à la diffusion de documents scientifiques de niveau recherche, publiés ou non, émanant des établissements d'enseignement et de recherche français ou étrangers, des laboratoires publics ou privés. 


\title{
Base free oxidation of 1,6-hexanediol to adipic acid over supported noble metal mono- and bimetallic catalysts
}

\author{
Modibo Mounguengui-Diallo, François Vermersch, Noémie Perret, Catherine Pinel, \\ Michèle Besson"
}

Univ Lyon, Univ Claude Bernard, CNRS, IRCELYON, UMR5256, Institut de recherches sur la catalyse et l'environnement de Lyon, 2 Avenue Albert Einstein, 69626

Villeurbanne, France

\begin{abstract}
1,6-Hexanediol is an emerging building-block chemical, which may be derived from biomass and can produce adipic acid for the synthesis of polymers. A series of supported Pt, Bi-Pt, Au, Pd, Au-Pd, and Au-Pt catalysts were prepared and evaluated in the aerobic oxidation of 1,6-hexanediol to adipic acid in aqueous solution without the addition of a base or an acid. The influences of various molar ratios of the metals in the bimetallic systems and the support $\left(\mathrm{C}, \mathrm{ZrO} \mathrm{O}_{2}\right)$ were studied. Under the conditions used, bismuth did not promote the catalytic perfor-mance of Pt catalysts. On the other hand, formation of an alloy of Au-Pd or Au-Pt made the catalysts very effective. A yield of adipic acid of ca. $96 \%$ was achieved at $70{ }^{\circ} \mathrm{C}$ under 40 bar of air over the Au-Pt catalyst supported on zirconia with a Au/Pt molar ratio of about 1 . Recycling tests revealed the possibility to use the catalyst up to 6 times without significant changes in its catalytic performance.
\end{abstract}

\section{Introduction}

Adipic acid is an important monomer, primarily used in the manufacture of nylon 6,6 in its fiber and resin forms. Other applications include polyurethanes, adipic esters as plasticizers in PVC, lubricants, food and cosmetic additives [1,2]. The annual world production was almost 2.8 million metric tons in 2014 and it is expected to further increase at a compound annual grow rate of more than $3 \%$ in the next few years [3,4]. It is mostly obtained from petroleum-based feedstocks through the oxidation of cyclohexane to produce a cyclohexanol-cyclohexanone mixture, known as KA Oil, which is subsequently oxidized to adipic acid with an excess of nitric acid. Despite progress in recovery and reuse [5] one drawback of this route is the production of the greenhouse gas $\mathrm{N}_{2} \mathrm{O}$ as by-product [6]. Alternative catalytic petrochemical routes [2] include the oxidation of cyclohexene with hydrogen peroxide [7-11], of cyclohexane with molecular oxygen [12-14], of cyclohexanol/one with air [15-17] or hydrogen peroxide $[18,19]$, or the double hydroformylation of 1,3-butadiene followed by oxidation [20].

The manufacture of bio-based adipic acid has emerged as an alternative to the petrochemical process [2,3,21,22]. For instance, Rennovia claimed a two-step catalytic process starting with the hydrogenation of 2,5-furandicarboxylic acid to tetrahydrofuran-2,5-dicarboxylic acid (yield of $88 \%$ ) followed by ring-opening to adipic acid (yield of 99\%), using acetic acid as solvent [23]. Rennovia also disclosed a patent for the conversion of glucose to adipic acid, involving selective catalytic aerobic oxidation of glucose to glucaric acid in water (66\% yield over $\mathrm{Pt} / \mathrm{SiO}_{2}$ ), that further undergoes hydrodeoxygenation to adipic acid in acetic acid using $\mathrm{PdRh} / \mathrm{SiO}_{2}$ and a halogen source (89\% yield) [24,25]; the process is currently in its development stage. Several companies (Verdezyne, BioAmber, Genomatica among others) are developing fermentation routes of glucose or fatty acids to adipic acid [26]. Combined biological-chemical processes have also been proposed using the carbohydrate fractions of lignocellulosic biomass as feedstock [27-30]. Bio-based cis,cis-muconic acid is then catalytically hydrogenated to adipic acid over Pt/C $[28,30]$, RuPt nanoparticles [29], or $\mathrm{Ni} / \mathrm{Al}_{2} \mathrm{O}_{3}$ [31] with excellent yield; but the main drawback is associated to the difficulty of initial separation and purification of muconic acid [21]. Another pathway is a two-step reaction with upgrading of levulinic acid-derived $\gamma$-valerolactone to pentenoic acid isomers on a silica/alumina catalyst and subsequent conversion to adipic acid on a palladium acetate catalyst in the presence of $\mathrm{CO}$ and water [2,21].

An interesting bio-based route to produce adipic acid could also be via the oxidation of bio-1,6-hexanediol (HDO). The synthesis of bioHDO has been widely studied using several catalytic chemical pathways: (i) the selective ring opening/hydrogenolysis of 2,5- tetrahydrofurandimethanol (synthesized from 2,5-hydroxymethylfurfural) [32-35], (ii) the selective hydrogenolysis of intermediate

\footnotetext{
* Corresponding author.

E-mail address: michele.besson@ircelyon.univ-lyon1.fr (M. Besson).
} 
tetrahydropyran-2-methanol [34,36,37], or its sequential dehydration/ hydration/hydrogenation [38], (iii) hydrogenolysis of sorbitol [39], or (iv) hydrogenation of levoglucosenone [40,41]. However, overall yields were still moderate $(25 \%-40 \%)$.

Conversion of 1,6-HDO to adipic acid was previously claimed using biological oxidation [42]. However, catalytic oxidation of alcohols or aldehydes with molecular oxygen using noble metal heterogeneous catalysts is also possible [43-47]. The application of this method for the oxidation of $\alpha, \omega$-diols in aqueous solution with base has been investigated previously. The oxidation of a $0.1 \mathrm{M} H \mathrm{HDO}$ in a $1 \mathrm{M} \mathrm{NaOH}$ aqueous solution over $\mathrm{Au} / \mathrm{C}$ catalyst gave a $97 \%$ sodium adipate yield [45]. A Pt/C catalyst in $0.35 \mathrm{M}$ acetic acid yielded $85 \%$ adipic acid after $24 \mathrm{~h}$ of reaction at $70{ }^{\circ} \mathrm{C}$ under $10 \mathrm{bar} \mathrm{O}_{2}$, and using a molar substrate/ metal ratio of $100[43,44]$. The advantage of $\mathrm{Pt}$ is that it can operate in neutral or acidic medium compared to gold-only catalyst formulations that require the use of a base [48]. However, rapid deactivation of the monometallic catalyst may occur by over-oxidation of the metal or by strongly adsorbed species on the catalyst surface [44,49].

The improvement brought by the addition of a second metal has been previously demonstrated for several reactions. The addition of $\mathrm{Bi}$ to noble metal enhances the resistance to deactivation by oxygen and may avoid the use of a base $[48,50,51]$. A Pt-Bi/C catalyst yielded $98 \%$ of adipic acid compared to only $46 \%$ over Pt/C after $36 \mathrm{~h}$ of reaction at $55^{\circ} \mathrm{C}$ under 0.2 bar $\mathrm{O}_{2}$ [46]. Conversely, (Pt-Sn/C) decreased adipic acid yield [52]. In fact, one of the difficulties of using bimetallic catalysts is that their structure can evolve over time during catalytic reaction, and in the case of $\mathrm{Pt}-\mathrm{Sn} / \mathrm{C}$, the lower production of adipic acid has been linked to the formation of a Pt-Sn alloy [52]. The alloying of Pd or $\mathrm{Pt}$ with $\mathrm{Au}$ has been shown in recent years to enhance significant activity and stability [53-58]. Supported Pt, Au, Pd and bimetallic catalysts have been claimed to oxidize aqueous solution of $0.1 \mathrm{M}$ 1,6-HDO to adipic acid with yields up to $99 \%$ at $140-160{ }^{\circ} \mathrm{C}$ in vials under pressure [47]. Independently of the metal used, the support may influence the catalytic performance. Even if most of the works for this catalytic reaction were carried out on active carbon support, the main drawback of this material is often its large surface area and its microporous volume that may lead to the significant adsorption of reaction products [44]. This is the reason why mesoporous $\mathrm{ZrO}_{2}$ will be used as support.

The objective of this work was to perform the catalytic oxidation of 1,6-hexanediol into adipic acid and to compare the catalytic activity and selectivity in neutral medium of the promising $\mathrm{C}$ and $\mathrm{ZrO}_{2}$ supported- Pt-Bi and Pt-Au and Pd-Au systems.

\section{Experimental}

\subsection{Catalyst preparation}

The supports used were activated carbon (CECA L3S, $900 \mathrm{~m}^{2} \mathrm{~g}^{-1}$, microporous) and $\mathrm{ZrO}_{2}$ (MEL Chemicals, XZO 632/18, $132 \mathrm{~m}^{2} \mathrm{~g}^{-1}$, mesoporous, average pore diameter $9 \mathrm{~nm}$ ).

The supported $\mathrm{Pt} / \mathrm{C}$ and $\mathrm{Pt} / \mathrm{ZrO}_{2}$ catalysts were prepared by wet impregnation of the support [59]. An aqueous solution of $\mathrm{H}_{2} \mathrm{PtCl}_{6}$ (Sigma-Aldrich, 99\% purity) containing the required amount of Pt was added dropwise under stirring to an aqueous suspension of the support under $\mathrm{N}_{2}$ bubbling at room temperature. After $5 \mathrm{~h}$, the slurry was cooled down in an ice bath and $50 \mathrm{~mL}$ of a $37 \mathrm{wt} \%$ formaldehyde solution was added, and then $20 \mathrm{~mL}$ of a $30 \mathrm{wt} \% \mathrm{KOH}$ solution. After stirring under $\mathrm{N}_{2}$ overnight, the solid was filtered and washed with water until neutrality of the filtrate. The catalysts were dried under $\mathrm{N}_{2}$ at $70{ }^{\circ} \mathrm{C}$ overnight.

The $\mathrm{Pt}-\mathrm{Bi} / \mathrm{C}$ and $\mathrm{Pt}-\mathrm{Bi} / \mathrm{ZrO}_{2}$ bimetallic catalysts were prepared from the monometallic catalysts via a surface redox reaction ensuring the deposition of bismuth on platinum, using $\mathrm{BiONO}_{3}$ or $\mathrm{BiNO}_{3}, 5 \mathrm{H}_{2} \mathrm{O}$ salts and glucose as reducing agent [50,59-61]. The monometallic Pt/C or $\mathrm{Pt} / \mathrm{ZrO}_{2}$ catalyst was suspended in an aqueous solution of glucose (glucose $/ \mathrm{Pt}=790$ ). An appropriate amount of $\mathrm{BiONO}_{3}$ or $\mathrm{BiNO}_{3}, 5 \mathrm{H}_{2} \mathrm{O}$ corresponding to the targeted loading was dissolved in $2 \mathrm{M} \mathrm{HCl}$ and was added into the suspension under nitrogen atmosphere. The $\mathrm{pH}$ was then increased to 9 by addition of $\mathrm{NaOH}$. Afterwards, the catalysts were filtered, washed, and dried under $\mathrm{N}_{2}$ at $70{ }^{\circ} \mathrm{C}$ overnight.

The Pt-Au and Pd-Au catalysts supported on $\mathrm{ZrO}_{2}$ were prepared by co-wet impregnation and $\mathrm{NaBH}_{4}$ reduction [62]. In a three-necked flask of $1 \mathrm{~L}$ the support was introduced in $500 \mathrm{~mL}$ of deionized water with mechanical stirring and bubbling of $\mathrm{N}_{2}$. An aqueous solution of $\mathrm{HAuCl}_{4}$ and $\mathrm{H}_{2} \mathrm{PtCl}_{6}$ (or $\mathrm{PdCl}_{2}$ ) corresponding to the desired metal amounts was added over a period of $1 \mathrm{~h}$ (yellow color) with moderate stirring (400 rpm). The suspension was then cooled in an ice bath and a solution of $\mathrm{NaBH}_{4}$ (20 mol. eq.) was added dropwise with vigorous stirring (800 rpm), which caused a sharp change of color towards black. After an additional $3 \mathrm{~h}$-stirring at $400 \mathrm{rpm}$, the solid was filtered, washed until a negative test with $\mathrm{AgNO}_{3}$, and dried under $\mathrm{N}_{2}$ at $70{ }^{\circ} \mathrm{C}$. Monometallic catalysts were prepared using the same protocol.

\subsection{Catalysts characterization}

The X-ray diffraction (XRD) patterns were recorded on a D8 Advance A25 diffractometer (Bruker) using a $\mathrm{CuK \alpha}$ source $(\lambda=1.54184 \AA)$. The crystalline phases were identified by reference to the JCPDS data files. The average crystallite size of the metal particles was calculated from line broadening according to Scherrer's equation using EVA and TOPAS software.

The metal loadings of the catalysts were determined by Inducted Coupled Plasma-Optical Emission Spectroscopy (ICP-OES) on a Activa Jobin-Yvon instrument. Prior to the analysis, the solids were solubilized in a mixture of $\mathrm{H}_{2} \mathrm{SO}_{4}$ and $\mathrm{HNO}_{3}$ at $250-300{ }^{\circ} \mathrm{C}$, and then in aqua regia at $150-200{ }^{\circ} \mathrm{C}$.

Transmission Electron Microscopy (TEM) and energy dispersive Xray spectroscopy (EDX) measurements were performed using a JEOL 2010 instrument operated at an accelerating voltage of $200 \mathrm{kV}$. The sample for TEM was prepared by ultrasonic dispersion in ethanol. A drop of dispersed catalyst was deposited onto the carbon-coated copper grid and the solvent was evaporated in air at room temperature. EDX was used to observe the composition of the catalysts.

\subsection{HDO oxidation catalytic test}

The catalytic oxidation reactions were carried out in a $300 \mathrm{~mL}$ batch reactor (Hastelloy) equipped with a magnetically driven gas inducing stirrer. The substrate (1,6-hexanediol, Alfa Aesar, 97\%) (1 M, $2.77 \mathrm{~g}$ in $150 \mathrm{~mL}$ of ultra-pure water) and the appropriate amount of catalyst that corresponds to a $\mathrm{HDO} /$ metal molar ratio of 100 were introduced into the reactor. After sealing and purging the reactor with Ar, the suspension was heated to $70{ }^{\circ} \mathrm{C}$, pressurized to 40 bar with air, and stirred at $1200 \mathrm{rpm}$, which corresponds to time zero. During the reaction, liquid samples were taken regularly via a sample diptube connected to a valve. After reaction, the autoclave was cooled and the catalyst was recovered by filtration through PVDF membrane $(0.45 \mu \mathrm{m})$.

Recycling tests were also performed. After an experiment, the used catalyst was filtered on a PVDF membrane $(0.45 \mu \mathrm{m})$, washed with water, dried at $70{ }^{\circ} \mathrm{C}$ under $\mathrm{N}_{2}$, and reused without reactivation. A loss of ca. $10 \%$ of the catalyst mass was unavoidable during this process. To perform the experiment with comparable mass of catalyst, the lost solid was replaced by part of the used catalyst of another experiment performed under the same conditions.

\subsection{Product analysis}

Liquid samples were analyzed using a HPLC Shimadzu-10A equipped with Photodiode Array (PDA) and differential refraction (RI) detectors in series, after filtration through a $0.45 \mu \mathrm{m}$ PVDF membrane and dilution by a factor 20 . Product separation was carried out with a 
Phenomenex Rezex ROA Acid $\mathrm{H}^{+}$column thermostated at $65{ }^{\circ} \mathrm{C}$ and with a $10 \mathrm{mM} \mathrm{H}_{2} \mathrm{SO}_{4}\left(0.6 \mathrm{~mL} \mathrm{~min}^{-1}\right)$ mobile phase. The retention times and the calibration curves for 6-hydroxyhexanoic acid (HA) and adipic acid (DA) were determined by injecting known concentrations of standard chemicals. 6-Hydroxyhexanal (ALD) and 6-oxohexanoic acid (AA) are not commercially available and were attributed to two other peaks, according to the order of appearance during the reaction. The lactone product of HDO ( $\varepsilon$-caprolactone) exhibited the same retention time as HA. If formed, it should be hydrolyzed in water to 6-hydroxyhexanoic acid whatever the $\mathrm{pH}$. Under similar reaction conditions, Ide et al. [44] also did not detect the formation of the lactone during oxidation of $\mathrm{HDO}$ over $\mathrm{Pt} / \mathrm{C}$ or $\mathrm{Pt}-\mathrm{Bi} / \mathrm{C}$ catalysts. Therefore, we considered that it was not formed during the reaction.

The total organic carbon (TOC) in solution was measured using a TOC analyzer (Shimadzu TOC- $\mathrm{V}_{\mathrm{CSH}}$ equipped with an ASI-automatic sampler). The carbon balance calculated from HPLC analysis was compared to the measured TOC values to verify the accuracy of the HPLC analysis. These values were further compared to the initial TOC value to check the possible adsorption on the catalytic solids or the degradation to gaseous products. The possible metal leaching of the catalyst was checked by ICP-OES of the final liquid reaction medium.

No conversion of HDO was observed in the blank test in the absence of either $\mathrm{C}$ or $\mathrm{ZrO}_{2}$ support or a catalyst, after $5 \mathrm{~h}$ of reaction under the selected reaction conditions. The supports did not show any activity. The selectivity to a specific product was defined as moles of that product divided by the moles of all formed products.

\section{Results and discussion}

\subsection{Supported Pt and Pt-Bi catalysts}

Powder XRD patterns of the carbon-supported Pt and Pt-Bi catalysts recorded in the $2 \theta$ range of $10-80^{\circ}$ are shown in Fig. S1. The determined metal loadings of the catalysts, the corresponding Bi/Pt molar ratios, and the determined average crystallite size of platinum are provided in Table 1.

The XRD pattern of $\mathrm{Pt}_{3.7} / \mathrm{C}$ (Fig. S1) showed diffraction peaks observed around $2 \theta=40^{\circ}, 45^{\circ}$, and $67^{\circ}$ that correspond to the (111), (200), and (222) planes of the face-centered cubic structure (fcc) of platinum (JCPDS 04-001-0112). The prominent broad bands centered at approximately $2 \theta=27^{\circ}$ and $43^{\circ}$ are attributed to amorphous carbon (JCPDS 00-23-0064). No peak characteristic of Bi species was observed, in agreement with the literature on Pt-Bi catalysts which shows that Bi species is usually not detectable by XRD over these Pt-Bi systems $[51,61]$. The lattice constant found for Pt was not influenced by the deposition of Bi whatever the Bi content ( $3.93 \AA$ ), which indicated that bismuth was not inserted in the framework of Pt and excluded the formation of Pt-Bi alloy by this preparation procedure. The average metal crystallite size of $\mathrm{Pt}$ in $\mathrm{Pt}_{3.7} / \mathrm{C}$ was ca. $4 \mathrm{~nm}$, it increased slightly with the deposition of increasing amounts of Bi (Table 1). Indeed, the deposition of Bi over noble metals such as Pt or Pd may lead to particle growth, depending on the method of preparation [60,61].

$\mathrm{Pt}_{3.7} / \mathrm{C}$ and the series of $\mathrm{Bi}$-modified catalysts were evaluated in the

Table 1

Characterization of supported Pt and Bi-Pt catalysts.

\begin{tabular}{lll}
\hline Catalyst & Bi/Pt mol. ratio & Pt crystallite size ${ }^{\mathrm{b}}(\mathrm{nm})$ \\
\hline $\mathrm{Pt}_{3.7} / \mathrm{C}$ & - & 4 \\
$\mathrm{Bi}_{0.9} \mathrm{Pt}_{3.5} / \mathrm{C}$ & 0.24 & 4 \\
$\mathrm{Bi}_{2.2} \mathrm{Pt}_{3.5} / \mathrm{C}$ & 0.59 & 6 \\
$\mathrm{Bi}_{3.7} \mathrm{Pt}_{3.5} / \mathrm{C}$ & 0.98 & 8 \\
$\mathrm{Pt}_{3.7} / \mathrm{ZrO}_{2}$ & - & 7 \\
$\mathrm{Bi}_{0.9} \mathrm{Pt}_{3.5} / \mathrm{ZrO}_{2}$ & 0.24 & 5
\end{tabular}

\footnotetext{
${ }^{\text {a }}$ Measured by ICP-OES.
}

b Calculated by XRD.
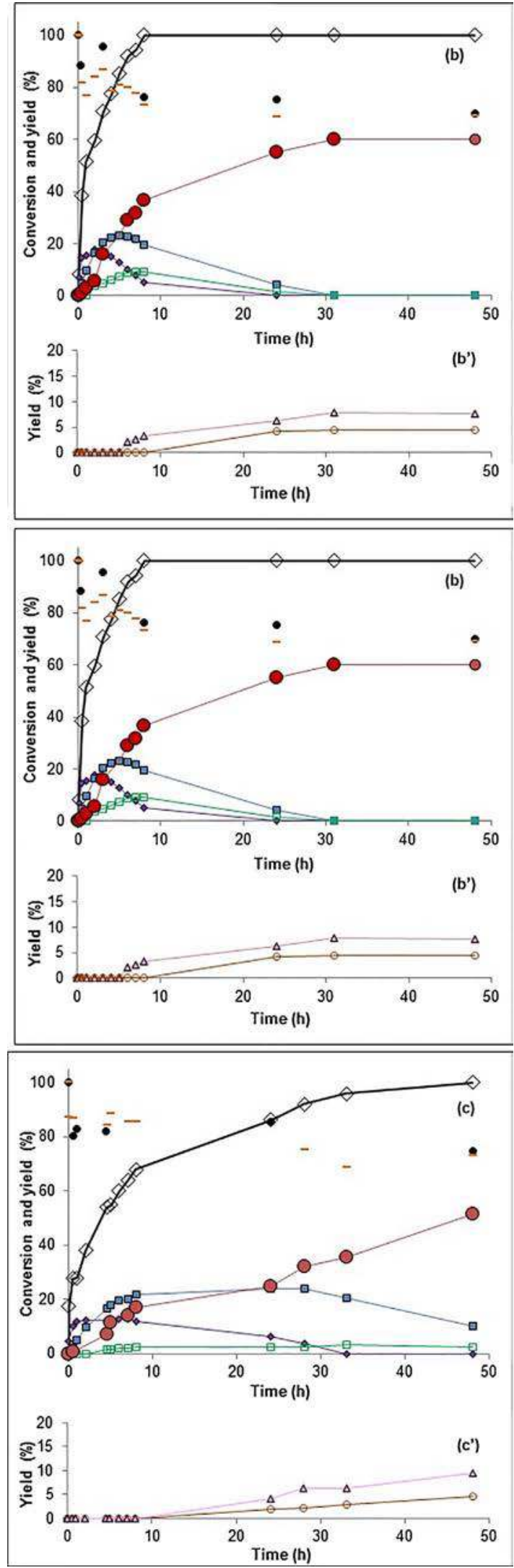

Fig. 1. Oxidation of 1,6-hexanediol (HDO) in water over (a and a') $\mathrm{Pt}_{3.7} / \mathrm{C}$, (b and b') $\mathrm{Bi}_{0.9} \mathrm{Pt}_{3.5} / \mathrm{C}(\mathrm{Bi} / \mathrm{Pt}=0.24)$, and $\left(\mathrm{c}\right.$ and $\left.\mathrm{c}^{\prime}\right) \mathrm{Bi}_{2.2} \mathrm{Pt}_{3.5} / \mathrm{C}(\mathrm{Bi} / \mathrm{Pt}=0.59) .(\diamond)$ Conversion,

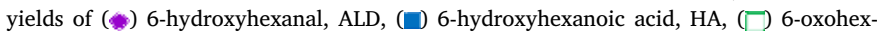
anoic acid, AA, ( ) adipic acid, DA, ( $($ ) glutaric acid, GLU, and ( $)$ succinic acid, SUC, and $(-)$ carbon balance, $(\bullet)$ TOC. Reaction conditions: $0.1 \mathrm{M} \mathrm{HDO,} \mathrm{HDO/Pt} \mathrm{molar}$ ratio $=100,70^{\circ} \mathrm{C}$, and 40 bar of air. 


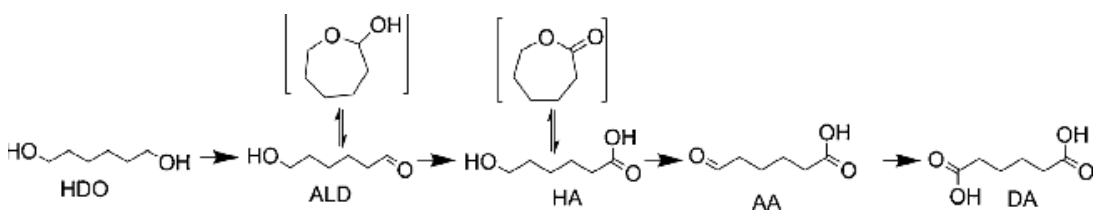

Scheme 1. Sequential oxidation of 1,6-hexanediol to adipic acid over

$\mathrm{Pt} / \mathrm{C}$ catalyst.

oxidation of 1,6-hexanediol (HDO) at $70^{\circ} \mathrm{C}$ under 40 bar of air (substrate $/ \mathrm{Pt}=100$ ). Fig. 1 shows the evolution of the reaction as a function of time over $\mathrm{Pt}_{3.7} / \mathrm{C}$ (Fig. 1a), $\mathrm{Bi}_{0.9}-\mathrm{Pt}_{3.5} / \mathrm{C}(\mathrm{Bi} / \mathrm{Pt}=0.24$, Fig. $1 \mathrm{~b}$ ), and $\mathrm{Bi}_{2.2} \mathrm{Pt}_{3.5} / \mathrm{C}(\mathrm{Bi} / \mathrm{Pt}=0.59$, Fig. 1c). The conversion of HDO, the yields of the different intermediates and of adipic acid (DA), carbon balance, and TOC are included Fig. 1.

Over $\mathrm{Pt}_{3.7} / \mathrm{C}$, HDO conversion was ca. $25 \%$ at time zero; however, no product other than HDO was detected by HPLC analysis, in agreement with TOC measured. This observation suggests strong adsorption of either HDO or the first partially oxidized products on the catalyst surface. Then, conversion of HDO under air was rapid and it was complete within $4 \mathrm{~h}$ of reaction. The intermediates detected were 6hydroxyhexanal (ALD), 6-hydroxyhexanoic acid (or 6-hydroxycaproic acid, HA), 6-oxohexanoic acid (AA) and adipic acid (DA). The main product at the beginning of the reaction was ALD, followed by the formation of HA, AA, and DA. The profiles of concentrations of the different products indicate that adipic acid was formed by sequential oxidation of 1,6-hexanediol as shown in Scheme Scheme 1. The diol is oxidized to the hydroxyaldehyde (ALD) and then to the hydroxyacid (HA). HA is further oxidized at the second alcohol function to the oxoacid (AA) and to the diacid (DA) product. Oxidation of the second alcohol group in HA was clearly less rapid than the oxidation of the first alcohol group in HDO. This general reaction pathway was also observed during oxidation of HDO in $0.35 \mathrm{M}$ acetic acid aqueous solution over $\mathrm{Pt} / \mathrm{C}$ [44]. As mentioned in the experimental part, neither the cyclic lactol nor $\varepsilon$-caprolactone were observed, because of the rapid interconversion with the open chains that were rapidly oxidized in water. Adipic acid was the major product after $3 \mathrm{~h}$. The yield of adipic acid increased over time as the different intermediates were oxidized to reach a final yield of ca. $60 \%$.

Results also indicated that degradation of the C6 oxygenated compounds occurred. Indeed, after about $3 \mathrm{~h}$ reaction time (HDO conversion above 95\%), glutaric acid (GLU) and succinic acid (SUC) were identified as secondary products (Fig. 1a', b', c') besides the expected products; their concentration increased to attain yields of GLU and SUC at $3.8 \%$ and $5.1 \%$, respectively. The final product DA was stable and did not undergo subsequent oxidative degradation, suggesting that the partially oxidized products were the precursors to the lower diacids GLU and SUC. The decarbonylation of an aldehyde function of ALD and AA to $\mathrm{CO}$ that subsequently can be oxidized to produce $\mathrm{CO}_{2}$ could be a possible pathway [44].

The carbon balance from HPLC analysis and the TOC data in liquid phase matched relatively well as a function of time, thus confirming the strong adsorption of the substrate or intermediates from the start of the reaction, and the occurrence of consecutive reactions contributing to the formation of GLU and SUC.

The profile of the reaction over the Bi-modified $\mathrm{Bi}_{0.9}-\mathrm{Pt}_{3.5} / \mathrm{C}$ catalyst $(\mathrm{Bi} / \mathrm{Pt}=0.24$; Fig. 1b-b') was not significantly different, albeit the reaction rates of oxidation of HDO and of intermediates were lowered. Indeed, complete conversion of HDO and the intermediates to DA was obtained before ca. $30 \mathrm{~h}$ of reaction vs. $22 \mathrm{~h}$ over $\mathrm{Pt}_{3.7} / \mathrm{C}$. The final yield of adipic acid was $61 \%$, similar to that over Pt/C. GLU and SUC were also formed on the Bi-modified catalyst and the yields after $48 \mathrm{~h}$ were of $4.4 \%$ and $7.7 \%$, respectively. A relatively fair agreement was also observed between the carbon balance and TOC; however, a significant gap compared to the initial TOC was still noticed, which confirms adsorption of products on the solid.

The addition of higher amounts of $\mathrm{Bi}$ over $\mathrm{Pt}_{3.7} / \mathrm{C}$ on the catalytic performance is further illustrated in Fig. 1c-c' for $\mathrm{Bi}_{2.2}-\mathrm{Pt}_{3.5} / \mathrm{C}(\mathrm{Bi} /$ $\mathrm{Pt}=0.59)$. The reaction rate of oxidation for the first primary alcohol group (which yields ALD) was much lower. Indeed, the time of reaction to achieve total conversion of HDO increased from $4 \mathrm{~h}$, for $\mathrm{Pt}_{3.7} / \mathrm{C}$, to $8 \mathrm{~h}$ and $48 \mathrm{~h}$ for $\mathrm{Bi}_{0.9}-\mathrm{Pt}_{3.5} / \mathrm{C}(\mathrm{Bi} / \mathrm{Pt}=0.24)$ and $\mathrm{Bi}_{2.2}-\mathrm{Pt}_{3.5} / \mathrm{C}(\mathrm{Bi} /$ $\mathrm{Pt}=0.59)$, respectively. GLU and SUC were observed as by-products. At a still higher $\mathrm{Bi} / \mathrm{Pt}$ molar ratio of $0.98\left(\mathrm{Bi}_{3.7} \mathrm{Pt}_{3.5} / \mathrm{C}\right.$, not shown), HDO conversion was only $65 \%$ after $48 \mathrm{~h}$.

To summarize, the addition of Bi had a detrimental effect on the reaction rate at $\mathrm{Bi} / \mathrm{Pt}>0.6$, hence on the final $\mathrm{DA}$ yield. The results may be discussed in relation to those of Davis et al, who also compared $\mathrm{Pt} / \mathrm{C}$ and Bi-promoted Pt/C in the oxidation of HDO ( $0.1 \mathrm{M}$ aqueous solutions) [43,44]. The impact of adding $\mathrm{Bi}$ to Pt depended on the $\mathrm{O}_{2}$ pressure. In the range of $0.2-2$ bar $\mathrm{O}_{2}$, different reaction orders with respect to $\mathrm{O}_{2}$ were obtained for $\mathrm{Pt} / \mathrm{C}$ (order of 0.75 ) and Bi-Pt/C (order close to zero), which accounted for the significant promotion effect of $\mathrm{Bi}$ on the reaction rate under low $\mathrm{O}_{2}$ pressures. Under higher $\mathrm{O}_{2}$ pressures (2-10 bar), the promotional effect of $\mathrm{Bi}$ was no more observed, and Bi-Pt/C became even less active. The present results (Fig. 2) are in agreement with the literature, as no promotional effect of Bi was observed under partial pressure of 8 bar of $\mathrm{O}_{2}$ ( 40 bar of air).

More generally, the reaction profiles of oxidation of HDO over the Bi-promoted catalysts supported on active carbon were relatively the same as over $\mathrm{Pt}_{3.7} / \mathrm{C}$ (Fig. 1). However, the Bi-Pt catalysts displayed a lowered rate for the oxidation of primary alcohol functions, either of HDO to ALD, or of HA to AA. Conversely, once formed, the oxo functional groups in the intermediates were rapidly converted to the carboxylic groups and yielded HA and DA. Finally, no improvement in the final yield of DA was noted compared with the $\mathrm{Pt}_{3.7} / \mathrm{C}$ catalyst (yield of ca. $60 \%$ ). The TOC and carbon balance showed the same trends as for $\mathrm{Pt}_{3.7} / \mathrm{C}$ : a satisfying carbon balance, but a strong adsorption of HDO and the first intermediates on the catalyst. Over all the carbon supported Pt catalysts, GLU and SUC were observed as by-products.

The influence of the nature of the support was examined by using $\mathrm{ZrO}_{2}$ as the support. The XRD patterns are shown in Fig. S1, and Table 1 summarizes the mean size of Pt crystallites, which are similar to the ones on active carbon. Fig. 2 displays the reaction profiles over $\mathrm{Pt}_{3.7} /$ $\mathrm{ZrO}_{2}$ and $\mathrm{Bi}_{0.9} \mathrm{Pt}_{3.5} / \mathrm{ZrO}_{2}(\mathrm{Bi} / \mathrm{Pt}=0.24)$.

Over both catalysts, the carbon balance and the TOC values were close, however, some loss of carbon in the aqueous phase in the form of adsorbed compounds or as gaseous products in the headspace of the reactor was evidenced. Comparison under identical conditions of carbon and zirconia- supported monometallic (Figs. 1a and Figure 2a) and Bi-modified catalysts (Fig. $1 \mathrm{~b}$ and Fig. 2b, respectively) shows that the reaction rate of $\mathrm{HDO}$ conversion was slightly faster using $\mathrm{ZrO}_{2}$ as the support; total conversion of HDO was achieved within $2 \mathrm{~h}$ over $\mathrm{Pt}_{3.7} / \mathrm{ZrO}_{2}$ (Fig. 2a) vs. $3 \mathrm{~h}$ over $\mathrm{Pt}_{3.7} / \mathrm{C}$ (Fig. $1 \mathrm{a}$ ), and within $3 \mathrm{~h}$ over $\mathrm{Pt}_{0.9}-\mathrm{Bi}_{3.5} / \mathrm{ZrO}_{2}$ (Fig. 2b) vs. $5 \mathrm{~h}$ over $\mathrm{Pt}_{0.9}-\mathrm{Bi}_{3.5} / \mathrm{C}$ (Fig. $1 \mathrm{~b}$ ). In contrast, the oxidation rates of the formed reaction intermediates were significantly slowed down over $\mathrm{ZrO}_{2}$ (Figs. 1 and 2). The maxima of ALD (formed after oxidation of one primary alcohol) and AA (oxidation of second $\mathrm{CH}_{2} \mathrm{OH}$ function) concentrations were higher than over the carbon support. Therefore, the oxidation of the aldehyde groups to the carboxylic ones were slower over the zirconia support.

Interestingly, glutaric and succinic acid were not detected over the $\mathrm{ZrO}_{2}$-supported catalysts, which suggests that the carbon support microporosity might be responsible for their formation. It was suggested in the literature that the presence of oxygen-function groups on a 

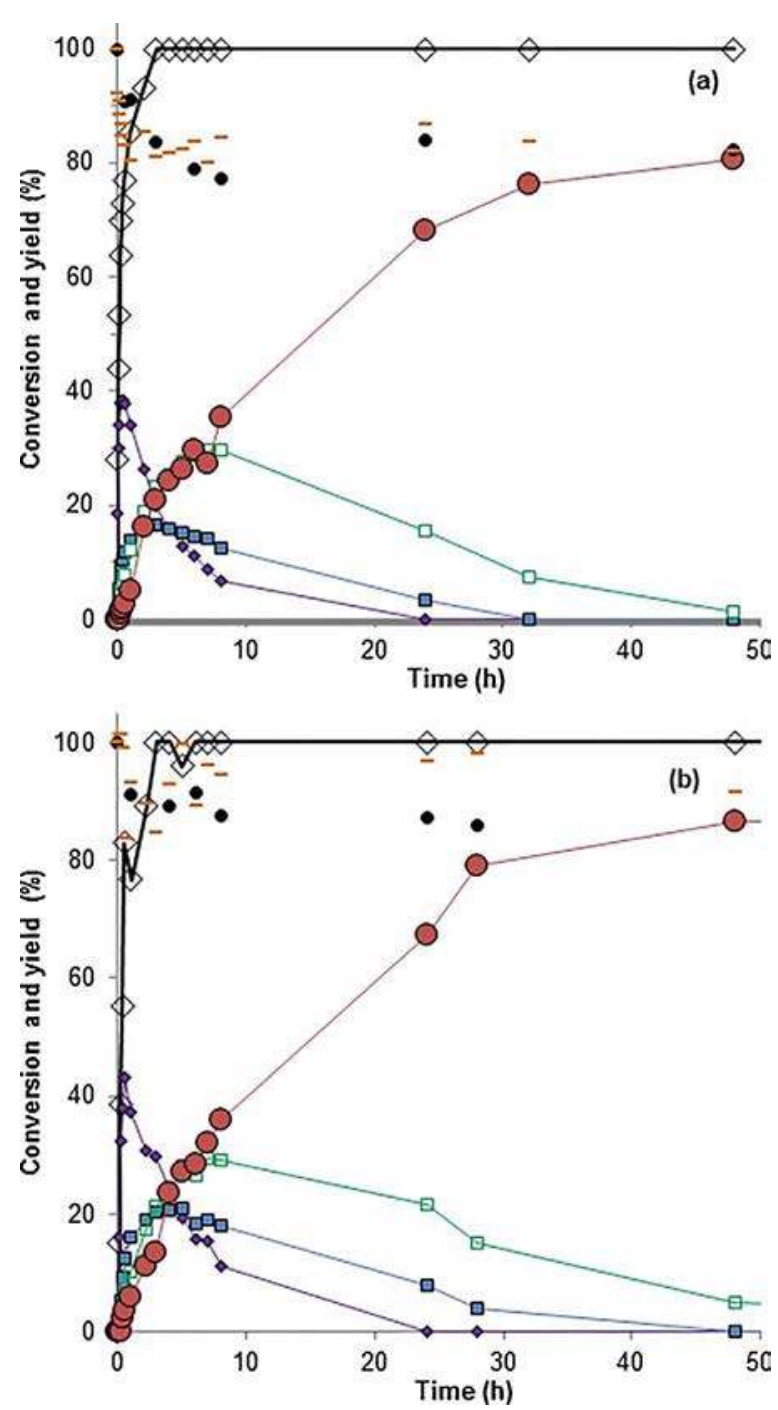

Fig. 2. Oxidation of 1,6-hexanediol (HDO) over (a) $\mathrm{Pt}_{3.7} / \mathrm{ZrO}_{2}$ and (b) $\mathrm{Bi}_{0.9} \mathrm{Pt}_{3.5} / \mathrm{ZrO}_{2}(\mathrm{Bi}$ / $\mathrm{Pt}=0.24) .(\diamond)$ Conversion, ( $)$ 6-hydroxyhexanal, ALD, ( $\square$ ) 6-hydroxyhexanoic acid,

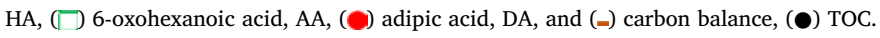
Reaction conditions: $0.1 \mathrm{M} \mathrm{HDO}, \mathrm{HDO} / \mathrm{Pt}$ molar ratio $=100,70^{\circ} \mathrm{C}, 40 \mathrm{bar}$ air.

carbon support may promote the hydrophilicity, and thus the adsorption of water or oxygenated compounds, and the conversion of adipic acid to glutaric and succinic acid over a Pt/C under air pressure [59]. In the present study, the support was not pre-oxidized before Pt deposition, so that this effect may be ruled out. Despite the fact that the reaction proceeded at a lower rate for intermediates up to DA over the $\mathrm{ZrO}_{2}$ supported catalyst, the final yield of DA reached $80 \%$. The absence of by-products may have contributed to this higher yield.

Fig. 3 summarizes the influence of the addition of different amounts of $\mathrm{Bi}$ on the final yields at $48 \mathrm{~h}$ for the series of $\mathrm{C}$ and $\mathrm{ZrO}_{2}$-supported catalysts. No positive effect of the promotion by Bi was noted.

Finally, ICP-OES analysis of the final reaction media revealed significant leaching of Pt-Bi bimetallic systems: approximately $13 \%$ of leaching of $\mathrm{Bi}$ was detected in the final reaction medium using $\mathrm{Bi}-\mathrm{Pt} / \mathrm{C}$ $(\mathrm{Bi} / \mathrm{Pt}=0.24)$, that is a weakness for their potential multiple reuse. Leaching of Pt was less than $2 \%$ of the loaded metal.

\subsection{Bimetallic $\mathrm{Au}-\mathrm{Pt} / \mathrm{ZrO}_{2}$ and $\mathrm{Au}-\mathrm{Pd} / \mathrm{ZrO}_{2}$ catalysts}

The series of bimetallic Au-Pt and Au-Pd catalysts were prepared on $\mathrm{ZrO}_{2}$ support to avoid formation of by-products (vide supra). The $\mathrm{Au} / \mathrm{Pt}$ or $\mathrm{Au} / \mathrm{Pd}$ molar ratios were chosen in a large range to detect an optimal

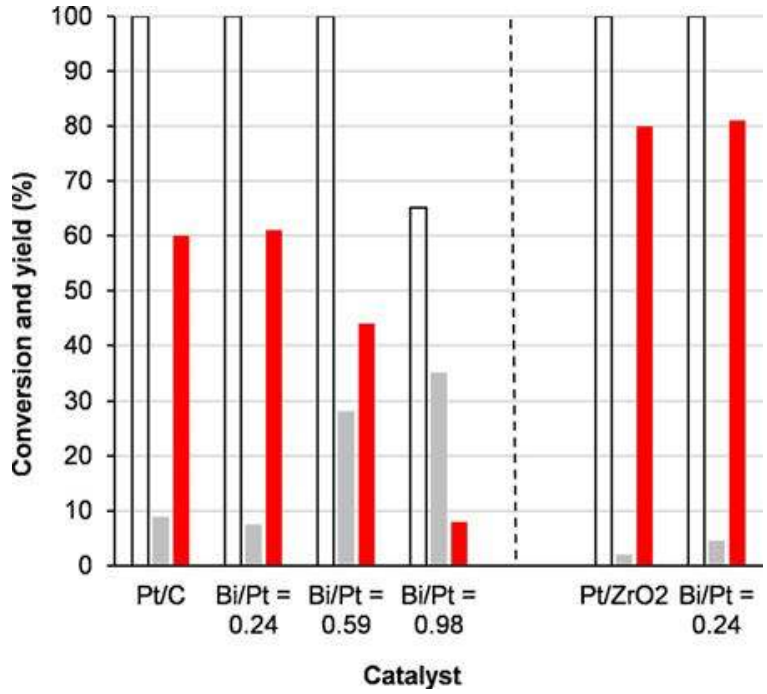

Fig. 3. Conversion and yields of products at $48 \mathrm{~h}$ over the Pt and Bi-Pt catalysts supported on $\mathrm{C}$ (left) or $\mathrm{ZrO}_{2}$ (right). Reaction conditions: $0.1 \mathrm{M} \mathrm{HDO}, \mathrm{HDO} / \mathrm{Pt}$ molar ratio $=100$, $70{ }^{\circ} \mathrm{C}, 40$ bar air. $(\square)$ HDO conversion, $(\square)$ yield of DA, ( $\square$ ) yield of partially oxidized products plus by-products.
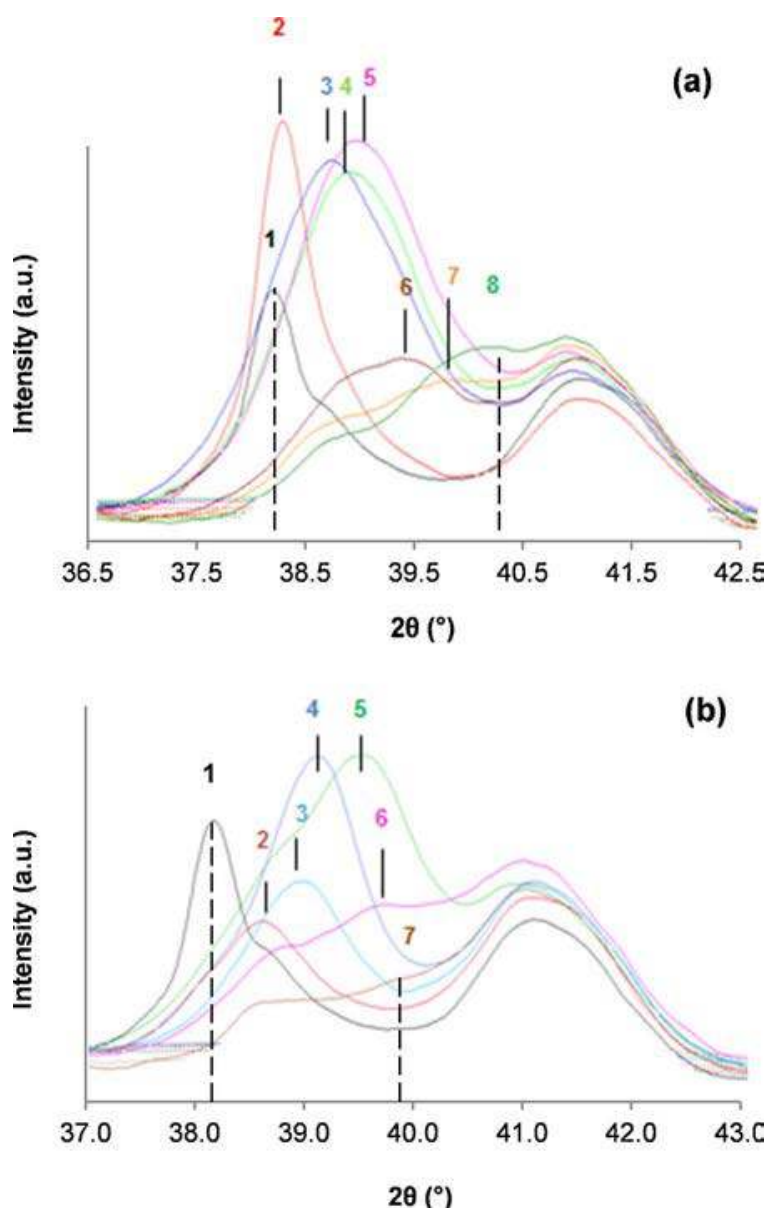

Fig. 4. Powder XRD patterns of zirconia supported (a) Au, Au-Pt, and Pt catalysts, and (b) $\mathrm{Au}, \mathrm{AuPd}$, and Pd catalysts. (1) $\mathrm{Au}_{3.6} / \mathrm{ZrO}_{2}$, (2) $\mathrm{Au}_{3.9} \mathrm{Pt}_{0.6} / \mathrm{ZrO}_{2}$ (6.4), (3) $\mathrm{Au}_{5.2} \mathrm{Pt}_{3.1} / \mathrm{ZrO}_{2}$ (1.66), (4) $\mathrm{Au}_{3.0} \mathrm{Pt}_{3.3} / \mathrm{ZrO}_{2}$ (0.9), (5) $\mathrm{Au}_{2.8} \mathrm{Pt}_{3.6} / \mathrm{ZrO}_{2}$ (0.77), (6) $\mathrm{Au}_{1.4} \mathrm{Pt}_{3.3} / \mathrm{ZrO}_{2}$ (0.42), (7) $\mathrm{Au}_{0.5} \mathrm{Pt}_{3.1} / \mathrm{ZrO}_{2}$ (0.16), (8) $\mathrm{Pt}_{3.7} / \mathrm{ZrO}_{2}$. (1) $\mathrm{Au}_{3.6} / \mathrm{ZrO}_{2}$ (1), $\mathrm{Au}_{1.0} \mathrm{Pd}_{3.5} \mathrm{ZrO}_{2}(\mathrm{Au} /$ $\mathrm{Pd}=4.14)$, (3) $\mathrm{Au}_{2.1} \mathrm{Pd}_{1.0} / \mathrm{ZrO}_{2}(\mathrm{Au} / \mathrm{Pd}=1.13)$, (4) $\mathrm{Au}_{2.5} \mathrm{Pd}_{1.6} / \mathrm{ZrO}_{2}(\mathrm{Au} / \mathrm{Pd}=0.84)$, (5) $\mathrm{Au}_{4.0} \mathrm{Pd}_{3.8} / \mathrm{ZrO}_{2}$ (0.57), (6) $\mathrm{Au}_{1.0} \mathrm{Pd}_{3.5} / \mathrm{ZrO}_{2}$ (0.15), (7) $\mathrm{Pd}_{3.1} / \mathrm{ZrO}_{2}$. The dashed lines represent the expected positions for the (111) peaks of $\mathrm{Au}, \mathrm{Pt}$, and $\mathrm{Pd}$. 
Table 2

Composition, particle size of $\mathrm{ZrO}_{2}$ supported $\mathrm{Pt}, \mathrm{Au}, \mathrm{Pd}$, Au-Pt, and Au-Pd catalysts.

\begin{tabular}{llll}
\hline Catalyst & $\mathrm{Au} / \mathrm{Pt}^{\mathrm{a}}$ or $\mathrm{Au} / \mathrm{Pd}^{\mathrm{a}}$ & Metal load $^{\mathrm{a}}(\%)$ & Crystallite size $^{\mathrm{b}}(\mathrm{nm})$ \\
\hline $\mathrm{Pt}_{3.7} / \mathrm{ZrO}_{2}$ & - & 3.7 & 7 \\
$\mathrm{Au}_{0.5} \mathrm{Pt}_{3.1} / \mathrm{ZrO}_{2}$ & 0.16 & 3.6 & 5 \\
$\mathrm{Au}_{1.4} \mathrm{Pt}_{3.3} / \mathrm{ZrO}_{2}$ & 0.42 & 4.7 & 5 \\
$\mathrm{Au}_{2.8} \mathrm{Pt}_{3.6} / \mathrm{ZrO}_{2}$ & 0.77 & 6.4 & 5 \\
$\mathrm{Au}_{3.0} \mathrm{Pt}_{3.3} / \mathrm{ZrO}_{2}$ & 0.90 & 6.3 & 5 \\
$\mathrm{Au}_{5.2} \mathrm{Pt}_{3.1} / \mathrm{ZrO}_{2}$ & 1.66 & 8.3 & 5 \\
$\mathrm{Au}_{3.9} \mathrm{Pt}_{0.6} / \mathrm{ZrO}_{2}$ & 6.40 & 4.5 & 9 \\
$\mathrm{Au}_{3.6} / \mathrm{ZrO}_{2}$ & - & 3.6 & 11 \\
$\mathrm{Au}_{1.0} \mathrm{Pd}_{3.5} / \mathrm{ZrO}_{2}$ & 0.15 & 4.5 & 3 \\
$\mathrm{Au}_{4.0} \mathrm{Pd}_{3.8} / \mathrm{ZrO}_{2}$ & 0.57 & 7.8 & 5 \\
$\mathrm{Au}_{2.5} \mathrm{Pd}_{1.6} / \mathrm{ZrO}_{2}$ & 0.84 & 4.1 & 9 \\
$\mathrm{Au}_{2.1} \mathrm{Pd}_{1.0} / \mathrm{ZrO}_{2}$ & 1.13 & 3.1 & 6 \\
$\mathrm{Au}_{2.3} \mathrm{Pd}_{0.3} / \mathrm{ZrO}_{2}$ & 4.14 & 2.6 & 4 \\
$\mathrm{Pd}_{3.1} / \mathrm{ZrO}_{2}$ & - & 3.1 & 6 \\
\hline
\end{tabular}

${ }^{\text {a }}$ Measured by ICP-OES.

${ }^{\mathrm{b}}$ Of the alloy, as calculated by XRD

composition. Fig. 4 shows the XRD patterns of the Au, Pt, Pd, Au-Pt, and Au-Pd catalysts in the $2 \theta$ ranges between 36.5 and $43^{\circ}$ typical of (111) reflections of $\mathrm{Au}, \mathrm{Pt}$ and $\mathrm{Pd}$. Table 2 summarizes the actual loadings of the catalysts, which were relatively close to the nominal loadings, and the mean crystallite size measured for the metals.

$\mathrm{Au}$ and Pd or Pt can form solid solutions over the whole range of atomic ratios. Bimetallic nanoparticles can generate different configurations (e.g. core-shell, alloy) [63]. Nevertheless, the preparation of supported bimetallic Au-Pt or Au-Pd by co-wet impregnation and reduction with $\mathrm{NaBH}_{4}$ usually leads to the formation of alloy [62,64]. Notably, the XRD patterns of all bimetallic catalysts clearly revealed the presence of the main (111) peak line which lies between the diffraction line of pure $\mathrm{Au}\left(2 \theta=38.2^{\circ}\right)$ and $\mathrm{Pt}\left(2 \theta=39.8^{\circ}\right)$, or Pd $\left(2 \theta=40.2^{\circ}\right)$ monophases (Fig. 4). In all samples, only a single alloy structure was observed and no other diffraction peak corresponding to Au or Pt (or $\mathrm{Pd}$ ) was recognized. This indicates the successful formation of Au-Pt and Au-Pd alloys. The shift of the diffraction peak decreased to lower diffraction angles with increasing Au content in the bimetallic systems (Fig. 4). The lattice parameters of Pt, Pd, and Au are $3.92 \AA, 3.89 \AA$, and $4.07 \AA$, respectively; the lattice parameters of the different bimetallic catalysts were estimated from the XRD diffraction pattern. They are plotted in Fig. S2 as a function of the Au amount in Au-Pd and Au-Pt catalysts. This figure also represents the linear relation obtained by applying Vegard's law to the Au-Pd and Au-Pt bimetallic systems. Increasing the concentration of Au led to an increase in the experimentally determined lattice distance with no significant deviation from Vegard's law, which indicates the presence of alloying [53,65,66].

The morphology of the Au-Pt and Au-Pd bimetallic nanoparticles were further characterized by TEM. Some representative recorded pictures of the supported $\mathrm{Au}-\mathrm{Pt}(\mathrm{Au} / \mathrm{Pt}=0.77)$ and $\mathrm{Au}-\mathrm{Pd}(\mathrm{Au} /$ $\mathrm{Pd}=0.84$ ) catalysts are shown in Fig. 5.

As shown previously for similar Au-Pt catalysts supported on $\mathrm{TiO}_{2}$ or $\mathrm{ZrO}_{2}$ using the same method of preparation [64], both Au-Pt and AuPd catalysts showed individual bimetallic nanoparticles and agglomerates forming nanochains of two or several nanoparticles of average size in the range from $5-10 \mathrm{~nm}$, in agreement with XRD results. EDX spectra acquired on different zones containing several metallic particles showed that both Au and Pt or Pd are present within the nanoparticles (Fig. $5 \mathrm{a} 3$ and b2). The relative $\mathrm{Au} / \mathrm{Pt}$ or $\mathrm{Au} / \mathrm{Pd}$ ratios determined by EDX (0.63 and 0.82 , respectively) were relatively close to the nominal composition resulting from ICP-OES analysis $(0.77$ and 0.84 , respectively), strongly supporting the formation of single-phase alloys.
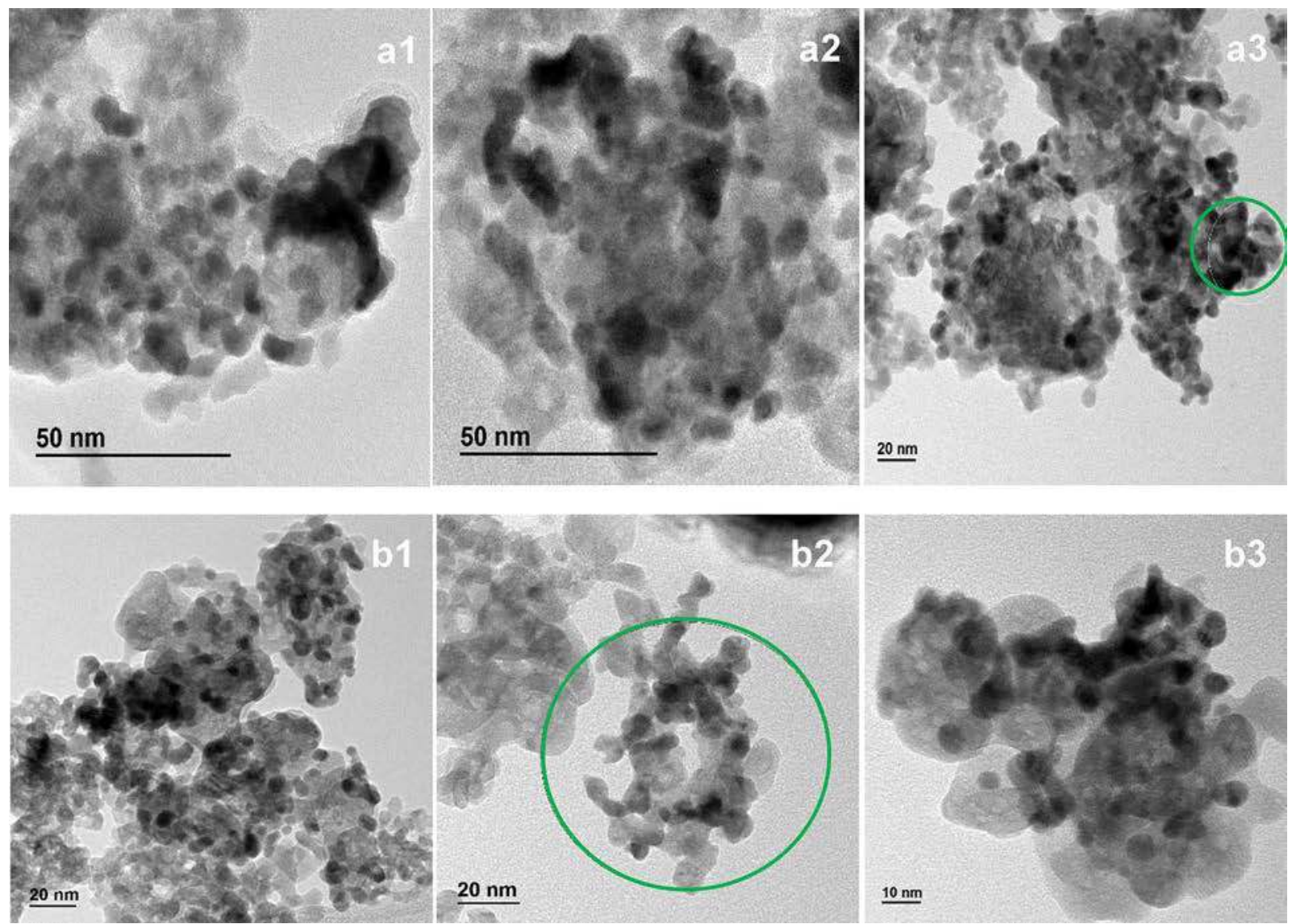

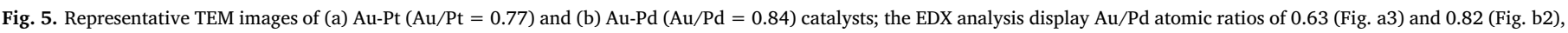
respectively. 

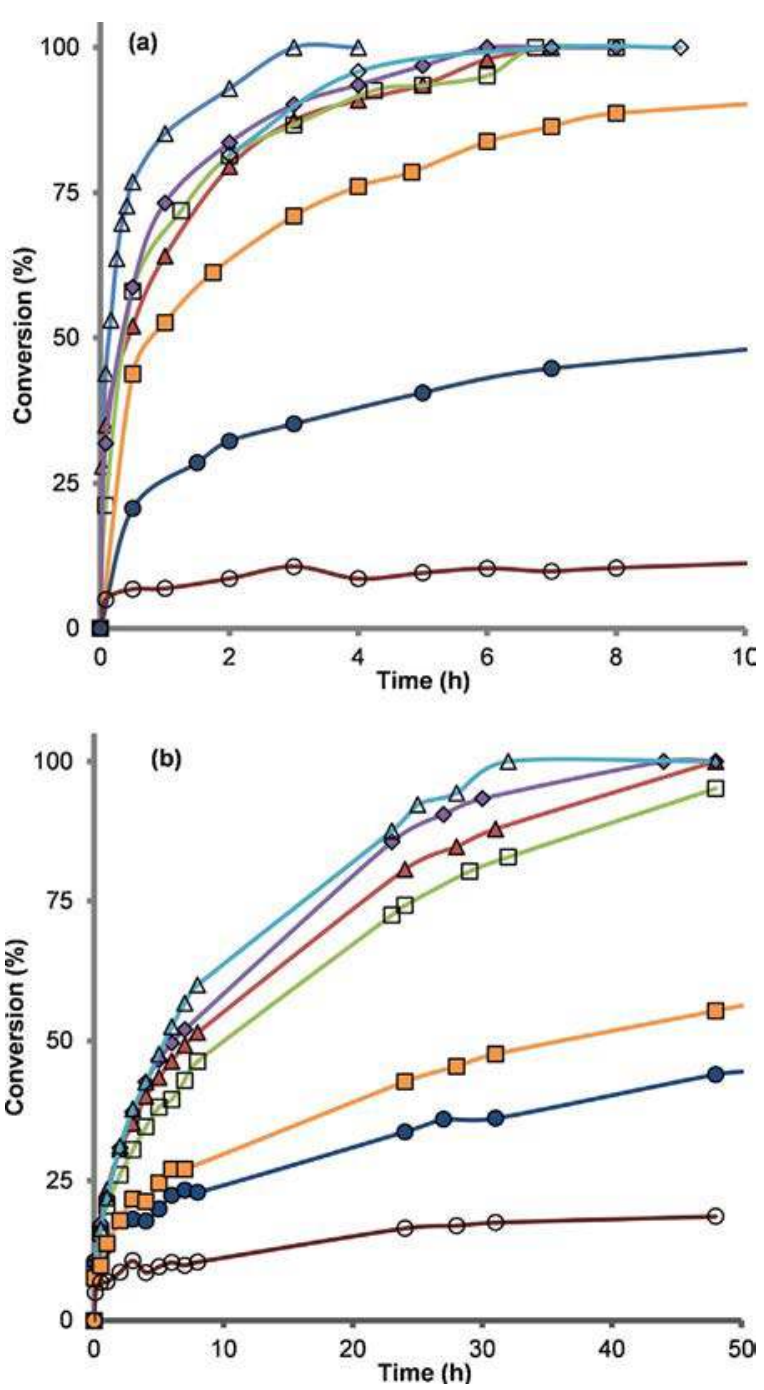

Fig. 6. HDO conversion as a function of time over supported- (a) Au, Au-Pt, and Pt catalysts: (O) $\mathrm{Au}_{3.6} / \mathrm{ZrO}_{2}$, (O) $\mathrm{Au}_{3.9} \mathrm{Pt}_{0.6} / \mathrm{ZrO}_{2}(\mathrm{Au} / \mathrm{Pt}=6.4)$, ( ) $\mathrm{Au}_{5.2} \mathrm{Pt}_{3.1} / \mathrm{ZrO}_{2}(\mathrm{Au} /$ $\mathrm{Pt}=1.66),(\diamond) \mathrm{Au}_{3.0} \mathrm{Pt}_{3.3} / \mathrm{ZrO}_{2}(\mathrm{Au} / \mathrm{Pt}=0.9),(\diamond) \mathrm{Au}_{2.8} \mathrm{Pt}_{3.6} / \mathrm{ZrO}_{2}(\mathrm{Au} / \mathrm{Pt}=0.77),(\square)$ $\mathrm{Au}_{1.4} \mathrm{Pt}_{3.3} / \mathrm{ZrO}_{2}(\mathrm{Au} / \mathrm{Pt}=0.42)$, ( $) \mathrm{Au}_{0.5} \mathrm{Pt}_{3.1} / \mathrm{ZrO}_{2}(\mathrm{Au} / \mathrm{Pt}=0.16),(\Lambda) \mathrm{Pt}_{3.7} / \mathrm{ZrO}_{2}$, and (b) Au, Au-Pd, and Pd catalysts: (O) $\mathrm{Au}_{3.6} / \mathrm{ZrO}_{2}$, (O) $\mathrm{Pd}_{3.1} / \mathrm{ZrO}_{2}$, $\left(\mathrm{Au}_{2.3} \mathrm{Pd}_{0.3} / \mathrm{ZrO}_{2}\right.$ $(\mathrm{Au} / \mathrm{Pd}=4.14),(\square) \mathrm{Au}_{4.0} \mathrm{Pd}_{3.8} / \mathrm{ZrO}_{2} \quad(\mathrm{Au} / \mathrm{Pd}=0.57)$, ( () $\mathrm{Au}_{1.0} \mathrm{Pd}_{3.5} / \mathrm{ZrO}_{2} \quad(\mathrm{Au} /$ $\mathrm{Pd}=0.15), \quad(\diamond) \quad \mathrm{Au}_{2.5} \mathrm{Pd}_{1.6} / \mathrm{ZrO}_{2} \quad(\mathrm{Au} / \mathrm{Pd}=0.84), \quad(\triangle) \quad \mathrm{Au}_{2.1} \mathrm{Pd}_{1.0} / \mathrm{ZrO}_{2} \quad(\mathrm{Au} /$ $\mathrm{Pd}=1.13)$. Reaction conditions: $\mathrm{HDO}(0.1 \mathrm{M}), \mathrm{HDO} / \mathrm{metal}=100,70^{\circ} \mathrm{C}, 40 \mathrm{bar}$ of air.

Fig. $6 \mathrm{a}$ and $\mathrm{b}$ compare the profiles of HDO conversion as a function of time over the series of $\mathrm{Au}-\mathrm{Pt} / \mathrm{ZrO}_{2}$ and $\mathrm{Au}-\mathrm{Pd} / \mathrm{ZrO}_{2}$ catalysts, respectively.

The catalytic activity was significantly affected by the composition. First, the monometallic catalysts exhibited very different reaction rates. $\mathrm{Pt}_{3.7} / \mathrm{ZrO}_{2}$ was fairly active (conversion was complete after $3 \mathrm{~h}$ ), whereas $\mathrm{Pd}_{3.1} / \mathrm{ZrO}_{2}\left(44 \%\right.$ conversion after $48 \mathrm{~h}$ ) and $\mathrm{Au}_{3.6} / \mathrm{ZrO}_{2}$ (only $17 \%$ conversion after $48 \mathrm{~h}$ ) were comparatively very poorly active. The higher activity for Pt catalyst is in line with its known activity for alcohol oxidation in neutral medium, as described for several alcohols such as glycerol, glyoxal and methanol [67]. In contrast, Au catalysts, and to some extent Pd catalysts, usually show very low or no activity in non-alkaline medium [68].

Upon addition of a small amount of $\mathrm{Au}$ to $\mathrm{Pt}$ and formation of an alloy, the reaction rate of HDO conversion was sensitively lower than over Pt. For instance, the time to attain $80 \%$ conversion was only $0.6 \mathrm{~h}$ over Pt vs. $2 \mathrm{~h}$ over $\mathrm{Au}_{0.5} \mathrm{Pt}_{3.1} / \mathrm{ZrO}_{2}(\mathrm{Au} / \mathrm{Pt}=0.14)$. Higher $\mathrm{Au} / \mathrm{Pt}$ molar ratio (up to 0.9 ) did not influence significantly the rate of reaction and total conversion of HDO was attained within 6-7 h of reaction.
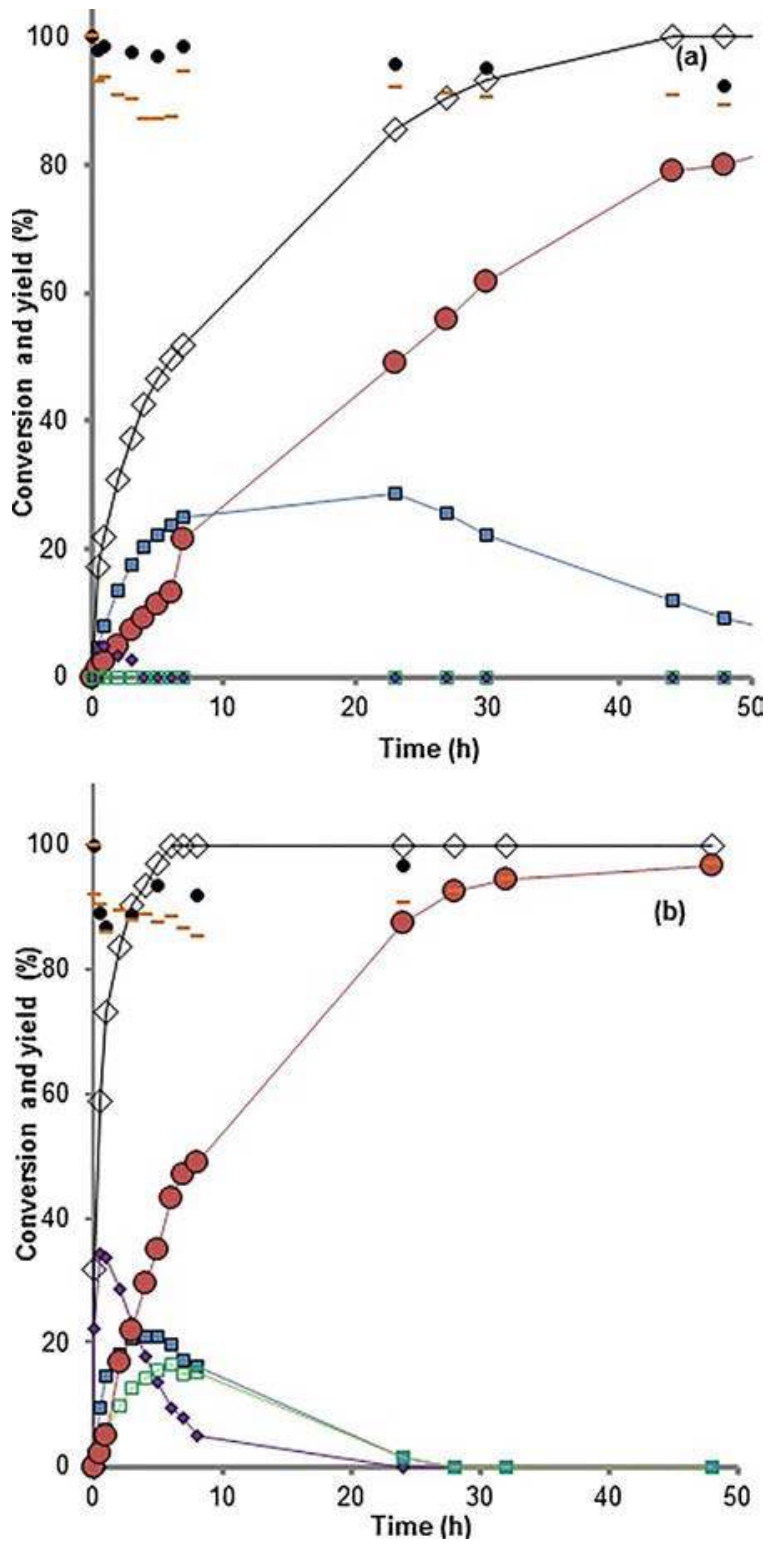

Fig. 7. HDO conversion and yields of products over (a) $\mathrm{Au}_{2.5} \mathrm{Pd}_{1.6} / \mathrm{ZrO}_{2}(\mathrm{Au} / \mathrm{Pd}=0.84)$ and (b) $\mathrm{Au}_{2.8} \mathrm{Pt}_{3.6} / \mathrm{ZrO}_{2}(\mathrm{Au} / \mathrm{Pt}=0.77)$. Reaction conditions: HDO (0.1 M), HDO/ metal $=100,70^{\circ} \mathrm{C}, 40 \mathrm{bar}$ of air. $(\diamond)$ Conversion, ( $)$ 6-hydroxyhexanal, ALD, ( 6 6-

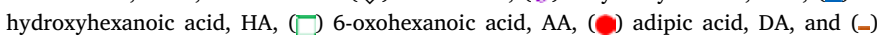
carbon balance, $(\bullet)$ TOC.

The activity then dropped drastically for $\mathrm{Au} / \mathrm{Pt}$ ratio of 1.66 and HDO conversion was even not complete after $48 \mathrm{~h}$ for $\mathrm{Au} / \mathrm{Pt}=6.4$.

The opposite trend was observed for activity with addition of Au to Pd vs. Pt. The Pd catalyst was little active for oxidation of HDO. The formation of the alloy significantly improved the reaction rate of HDO conversion (Fig. 6b). However, the Au-Pd catalysts remained much less active than the Au-Pt catalysts under the same reaction conditions (Fig. 6a and b).

Fig. 7 shows the reaction profiles as a function of time over a Au-Pd catalyst, namely $\mathrm{Au}_{2.5} \mathrm{Pd}_{1.6} \mathrm{ZrO}_{2}$ (Fig.7a, $\mathrm{Au} / \mathrm{Pd}=0.84$ ), and over a AuPt catalyst, namely catalyst $\mathrm{Au}_{2.8} \mathrm{Pt}_{3.6} / \mathrm{ZrO}_{2}$ (Fig. 7b, $\mathrm{Au} / \mathrm{Pt}=0.77$ ). Fig. 8 illustrates HDO conversion and yields of intermediates and byproducts at $48 \mathrm{~h}$ of reaction for the monometallic catalysts and the series of $\mathrm{Pt}-\mathrm{Au} / \mathrm{ZrO}_{2}$ and $\mathrm{Pd}-\mathrm{Au} / \mathrm{ZrO}_{2}$ bimetallic catalysts.

Over Au-Pd/ $/ \mathrm{ZrO}_{2}$, the oxidation reactions of the aldehyde groups to the acids were so rapid that the maximum yields of ALD (5\%) and AA (nul) were very low (Fig. 7a). These observations show that the relative 

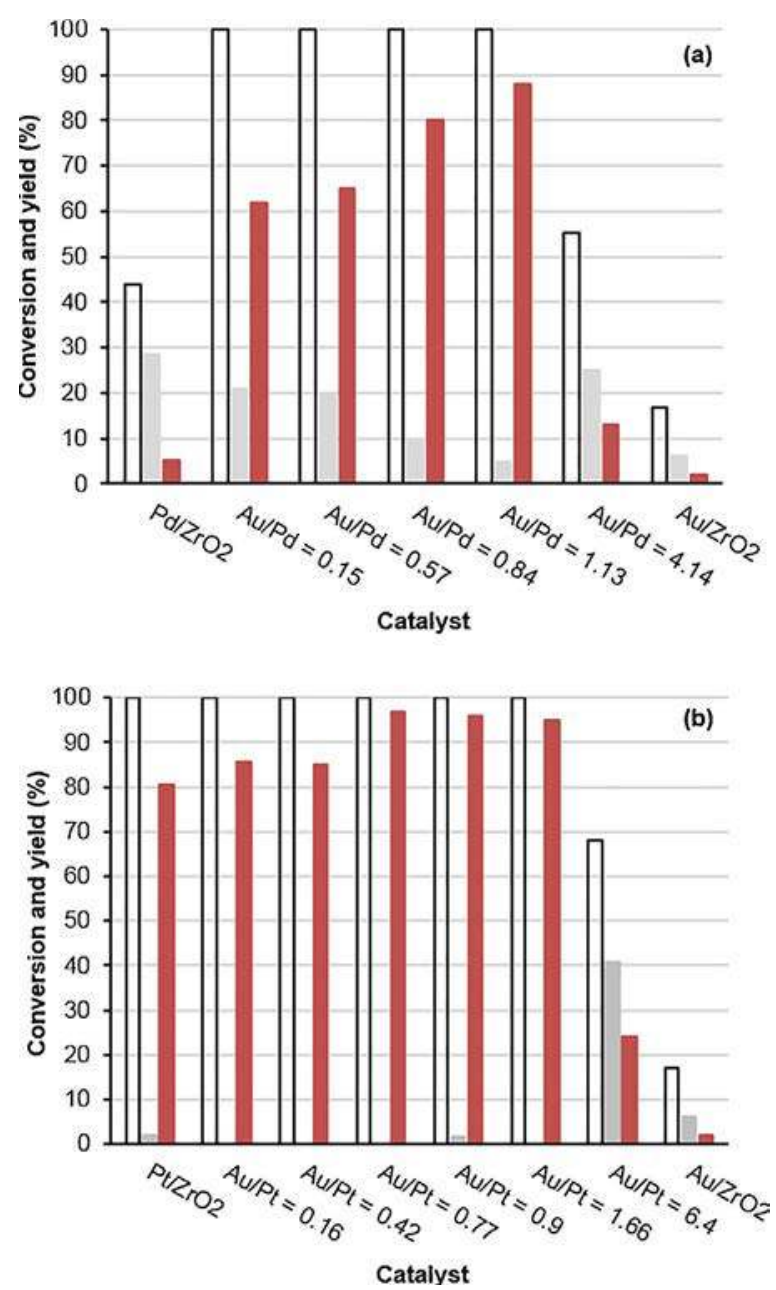

Fig. 8. Effect of catalyst composition on $(\square)$ HDO conversion, $(\square)$ yield of DA, and ( $)$ yield of partially oxidized products (ALD, HA, AA) after $48 \mathrm{~h}$ reaction over mono and bimetallic catalysts under the reaction conditions: $\mathrm{HDO}(0.1 \mathrm{M}), \mathrm{HDO} /$ metal $=100,70^{\circ} \mathrm{C}$, 40 bar of air.

rates of oxidation of the different functions (alcohol or aldehyde) were different. Conversion of the intermediates, predominantly HA, was not complete after $48 \mathrm{~h}$ of reaction. The maximum yield of DA of $80-88 \%$ after $48 \mathrm{~h}$ was observed for catalysts containing a $\mathrm{Au} / \mathrm{Pd}$ ratio of ca. 1 (Fig. 8a) which were also the most active. The reaction was slow over Au-Pd, however, when the reaction was allowed to continue for $120 \mathrm{~h}$, the final yield attained $95 \%$ and all intermediates were converted (not shown). Moreover, an increase of the temperature from $70{ }^{\circ} \mathrm{C}$ to $90{ }^{\circ} \mathrm{C}$ resulted in a final DA yield of $96 \%$ after $30 \mathrm{~h}$ over $\mathrm{Au}_{2.5} \mathrm{Pd}_{1.6} / \mathrm{ZrO}_{2}(\mathrm{Au} /$ $\mathrm{Pd}=0.84$ ), (not shown).

Over AuPt/ZrO ${ }_{2}, \mathrm{HDO}$ was rapidly converted (within $8 \mathrm{~h}$ ) and the rate of conversion of the intermediates was slower (Fig. 7b). A similar pathway upon conversion of HDO was observed as the one presented previously over Pt catalysts and thus, regardless of the second metal (Bi, $\mathrm{Au}$ ), and of the support: sequential oxidation reactions occurs from the diol to the diacid product with a final yield of $97 \%$. Over all Pt catalysts the rate of oxidation of HDO was much faster than the one of HA oxidation. Despite the six carbon length of the molecule, the proximity of a $\mathrm{COOH}$ group lowered the further oxidation of the second primary alcohol. No significant concentrations of AA were observed, therefore, the oxidation of the aldehyde function of AA is not the limiting step. The yield of DA after $48 \mathrm{~h}$ increased progressively from $80 \%$ over the Pt catalyst to a wide maximum of $95-97 \%$ for $\mathrm{Au} / \mathrm{Pt}$ molar ratio range $0.77-1.66$ and decreased rapidly to $24 \%$ after $48 \mathrm{~h}$ upon further addition of $\mathrm{Au}(\mathrm{Au} / \mathrm{Pt}=6.4)$, since reaction was then too slow and $40 \%$ of partially oxidized intermediates were still present (Fig. 8b). Taking also into consideration the reaction rates (Fig. 6a), the best compromise seems to be a $\mathrm{Au} / \mathrm{Pt}$ ratio of ca. 1 .

Moreover, neither GLU nor SUC were formed over the $\mathrm{ZrO}_{2}$-supported bimetallic Au-Pt and Au-Pd catalysts, the carbon balance and TOC values were always above $90 \%$.

In summary, Au-Pd (Fig. 8a) and Au-Pt (Fig. 8b) bimetallic catalysts with a metal molar ratio around 1 allowed to achieve the best yield of diacid (Fig. 8). It is worth to note that Au-Pd catalysts could efficiently catalyze the oxidation reaction of HDO in water to completion in the absence of any soluble base, as usually required. For instance, active carbon or titania-supported Au-Pd alloyed nanoparticles showed better performances for oxidation of glycerol to glycerate or HMF to furandicarboxylate, however a base promoter was employed in the systems [53,69-71]. The high conversions which were sometimes claimed under base-free conditions for Au or Au-Pd catalysts supported on basic supports (hydrotalcite, $\mathrm{MgO}$ ) were likely due to the extensive leaching of magnesium from the support and formation of $\mathrm{Mg}(\mathrm{OH})_{2}$ acting as the soluble base [48,72]. Selective oxidation of conjugated alcohols (benzyl alcohol, crotyl alcohol, cinnamyl alcohol) to the aldehydes was possible in aqueous solution in the absence of base additives using Au-Pd coreshell nanoparticles [73]. A recent report suggests that bimetallic Au-Pd nanoparticles supported on carbon nanotubes may obviate this requirement of an excess amount of a soluble base for 5-HMF oxidation to FDCA [74]. The better activity of Au-Pd and Au-Pt compared with the monometallic counterparts for oxidation of butanediols in base-free aqueous media was attributed to the presence of alloys [75]. In the present work, the Au-Pt catalysts supported on zirconia were the most active under these conditions $\left(70^{\circ} \mathrm{C}, 40 \mathrm{bar}\right.$ of air, water). The yields of adipic acid observed (96\%) are among the best ones described in the literature.

To gain more insight into the role of the metals on the reactions, Fig. 9 records the evolution of selectivity to each intermediate and to the diacid as a function of $\mathrm{HDO}$ conversion at $70^{\circ} \mathrm{C}$ under $40 \mathrm{bar}$ air over catalysts with different composition.

It shows that the distribution of products across the conversion of HDO depends strongly on the catalyst composition. At low conversion, the initial selectivity to 6-hydroxyhexanal (ALD) is high over the platinum-based catalysts and the oxidation of the aldehyde group of this intermediate takes place smoothly (Fig. 9a-c). A high selectivity to ALD at $90 \%$ HDO conversion over a Pt/C catalyst was observed during oxidation of $\alpha, \omega$ - diols to diacids at acidic conditions [16]. On the contrary, in the presence of $\mathrm{Au}_{2.5} \mathrm{Pd}_{1.6} / \mathrm{ZrO}_{2}$, this intermediate is very rapidly converted to 6-hydroxyhexanoic acid (HA), which is consequently formed with a high initial selectivity (Fig. 9d). Similarly, over this Au-Pd catalyst the oxidation of the aldehyde group of the subsequent intermediate oxohexanoic acid AA is very rapid so that it was almost not detected. It is clear that $\mathrm{Au}-\mathrm{Pd} / \mathrm{ZrO}_{2}$ catalysts are very active for the oxidation of the aldehyde functions, which affects the reaction profiles of HDO oxidation over Au-Pd vs. Pt-based catalysts. In the latter cases, selectivity to adipic acid becomes significant only at high diol conversion.

\subsection{Catalyst recyclability}

To investigate the stability of the catalysts, recycling experiments were performed over $\mathrm{Au}_{2.8} \mathrm{Pt}_{3.6} / \mathrm{ZrO}_{2}(\mathrm{Au} / \mathrm{Pt}=0.77)$ catalyst. The sample was used for 6 successive reactions and the corresponding results are displayed in Fig. 10. No significant loss of catalytic activity was observed. The yield of DA after $48 \mathrm{~h}$ was still $>86 \%$ in the 6 th experiment and the reaction mixture contained a few percent of HA and $\mathrm{AA}$ remaining to be converted. Moreover, no Au or Pt was detected in the post-reaction solution by ICP-OES analysis, indicating high chemical stability of the catalyst.

Furthermore, comparison of the diffraction patterns of different used catalysts and of the fresh ones indicates that the alloy phase was 

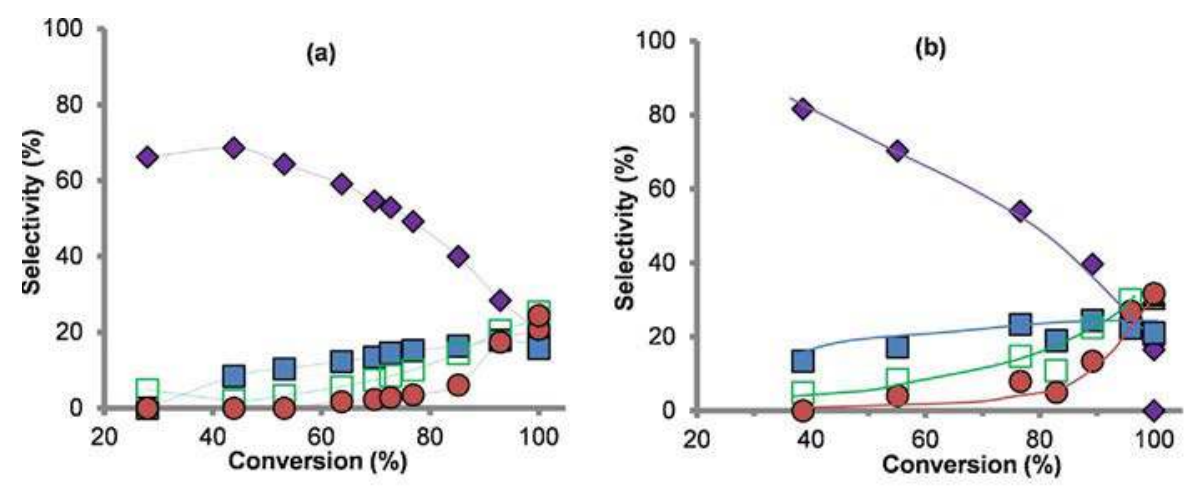

Fig. 9. Evolution of the selectivity to (4) ALD, $(\square) \mathrm{HA},(\square)$ $\mathrm{AA}$, and (C) DA as a function of $\mathrm{HDO}$ conversion over (a) $\mathrm{Pt} /$ $\mathrm{ZrO}_{2}$, (b) $\mathrm{Bi}_{0.9} \mathrm{Pt}_{3.5} / \mathrm{ZrO}_{2}$, (c) $\mathrm{Au}_{2.8} \mathrm{Pt}_{3.6} / \mathrm{ZrO}_{2}$ and (d) $\mathrm{Au}_{2.5} \mathrm{Pd}_{1.6} / \mathrm{ZrO}_{2}$ at $70{ }^{\circ} \mathrm{C}$ under 40 bar of air.
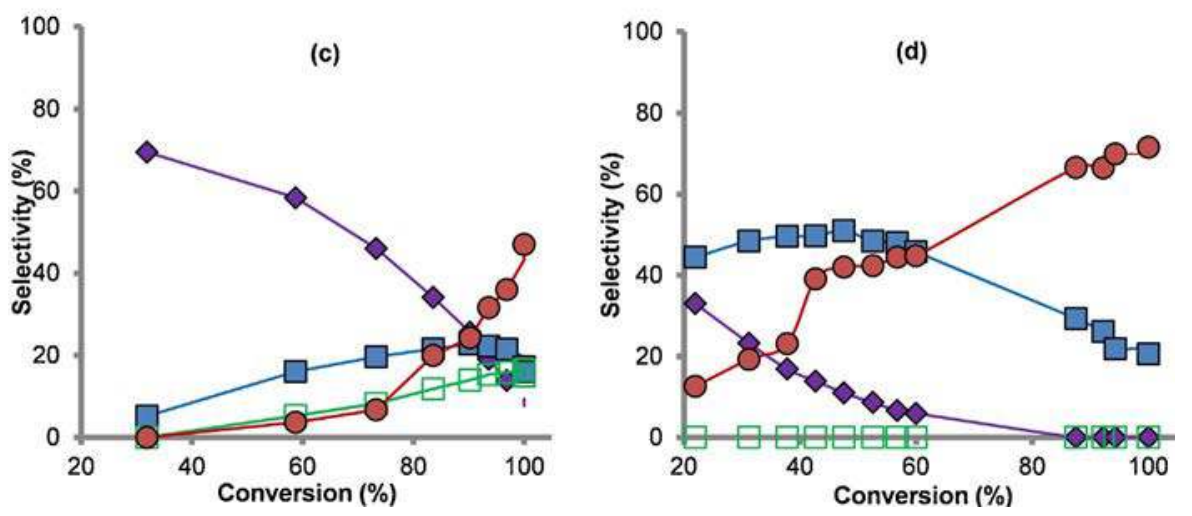

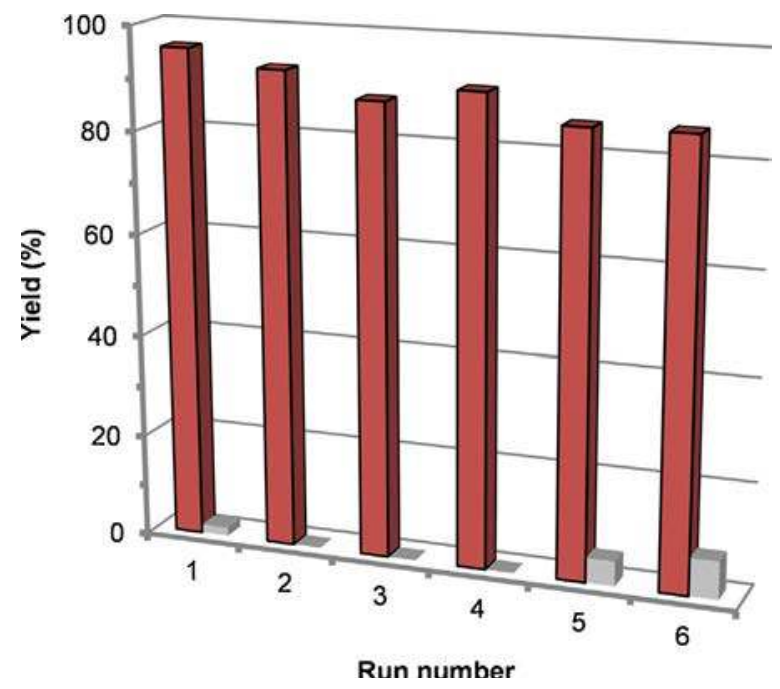

Fig. 10. Recyclability of $\mathrm{Au}_{2.8} \mathrm{Pt}_{3.6} / \mathrm{ZrO}_{2}(\mathrm{Au} / \mathrm{Pt}=0.77)$ in the oxidation of $1,6-\mathrm{HDO}$ to adipic acid. Reaction conditions: $\mathrm{HDO}(0.1 \mathrm{M}), \mathrm{HDO} / \mathrm{metal}=100,70{ }^{\circ} \mathrm{C}, 40 \mathrm{bar}$ of air. ( ) yield of DA, $(\square$ ) yield of partially oxidized products (HA, AA).

not modified, in particular in the $2 \theta$ range $37-43^{\circ}$, and the mean crystallite size of the alloys remained constant at $5 \mathrm{~nm}$ (Figs. S3 and S4).

\section{Conclusions}

The aerobic oxidation of 1,6-hexanediol to adipic acid in water was examined under base-free conditions over supported Pt, Bi-Pt, Pd, Au, Au-Pd and Au-Pt nanoparticles. The reaction of HDO went through sequential oxidation reactions; first one alcohol function is oxidized to the acid via the aldehyde, then the second one. Bimetallic Au-Pd and Au-Pt catalysts on zirconia are highly effective. The Au-Pt catalysts have been shown to have higher catalytic activity than Au-Pd. The highest yields of $96 \%$ of the desired dicarboxylic acid was reached for the catalysts having a $\mathrm{Au} / \mathrm{Pd}$ or $\mathrm{Au} / \mathrm{Pt}$ atomic ratio of ca. 1 .
Furthermore, the Au-Pt catalyst showed good stability and maintained a high performance over 6 runs. To our knowledge, this is one of the best result in the absence of base for aerobic oxidation of 1,6-hexanediol, which opens a route to sustainable oxidation of this family of substrates.

\section{Acknowledgements}

This work was financially supported by the Agence Nationale de la Recherche (ANR) within the French-Luxembourg program under Award Number ANR-15-CE07-0017-02, ANR Catbiose. The authors gratefully acknowledge Denilson Da Silva Perez (FCBA, France) and Youssef Habibi (LIST, Luxembourg) for fruitful discussions.

\section{Appendix A. Supplementary data}

Supplementary material related to this article can be found, in the online version, at doi:https://doi.org/10.1016/j.apcata.2017.12.005

\section{References}

[1] P. Oppenheim, G.L. Dickerson, Kirk-othmer encyclopedia of chemical technology, 5th edition, Adipic Acid 1 John Wiley \& Sons, 2004, pp. 553-582.

[2] S.V. de Vyver, Y. Roman-Leshkov, Catal.. Sci. Technol. 3 (2013) 1465-1479.

[3] R. Beerthuis, G. Rothenberg, N.R. Shiju, Green Chem. 17 (2015) 1341-1361.

[4] Adipic Acid Market Analysis By Application (Nylon 6,6 Fiber, Nylon 6,6 Resin, Polyurethane, Adipate Ester) And Segment Forecasts To 2020, Published: February 2014, 90 Pages, Report ID: 978-1-68038-078-1.

[5] T.N. Smith, K.R. Hash, Carbohydr. Res. 350 (2012) 6-13.

[6] B.G. Hermann, K. Blok, M.K. Patel, Environ. Sci. Technol. 41 (2007) 7915-7921.

[7] K. Sato, M. Aoki, R. Noyori, Science 281 (1998) 1646-1647.

[8] R. Noyori, M. Aoki, K. Sato, Chem. Commun.. (2003) 1977-1986.

[9] S. Ghosh, S.S. Acharyya, S. Adak, L.S. Konathala, T. Sasaki, R. Bal, Green Chem. 16 (2014) 2826-2834.

[10] L. Meng, S. Zhai, Z. Sun, F. Zhang, Z. Xiao, Q. An, Microporous Microporous Mater. 204 (2015) 123-130.

[11] J. Dai, W. Zhong, W. Yi, M. Liu, L. Mao, Q. Xu, D. Yin, Appl. Catal. B-Environ. 192 (2016) 325-341.

[12] R.F. Parton, I.F.J. Vankelecom, M.J.A. Casselman, C.P. Bezoukhanova, J.B. Uytterhoeven, P.A. Jacobs, Nature 370 (1994) 541-544.

[13] D. Bonnet, T. Ireland, E. Fache, J.-P. Simonato, Green. Chem. 8 (2006) 556-559. 
[14] A. Alshammari, A. Koeckritz, V.N. Kalevaru, A. Bagabas, A. Martin, ChemCatChem 4 (2012) 1330-1336.

[15] M. Besson, F. Gauthard, B. Horvath, P. Gallezot, J. Phys. Chem. B 109 (2004) 2461-2467.

[16] F. Cavani, L. Ferroni, A. Frattini, C. Lucarelli, A. Mazzini, K. Raabova, S. Alini, P. Accorinti, P. Babini, Appl. Catal. A: Gen. 391 (2011) 118-124.

[17] A. Dutta, M. Pramanik, A.K. Patra, M. Nandi, H. Uyama, A. Bhaumik, Chem. Commun. 48 (2012) 6738-6740.

[18] Y. Usui, K. Sato, Green Chem. 5 (2003) 373-375.

[19] M. Moudjahed, L. Dermeche, S. Benadji, T. Mazari, C. Rabia, J. Mol. Catal. Chem. 414 (2016) 72-77.

[20] A. Castellan, J. Bart, S. Cavallaro, Catal. Today 9 (1991) 255-283.

[21] J. Han, Energy Convers. Manage. 129 (2016) 75-80.

[22] S. Gunukula, R.P. Anex, Biofuels Bioprod. Bioref. 11 (2017) 897-907.

[23] T.R. Boussie, E.L. Dias, Z.M. Fresco, V.J. Murphy, Production of adipic acid and derivatives from carbohydrate-containing materials. US Pat. 2010/0317822 (2010), to Rennovia.

[24] T.R. Boussie, E.L. Dias, Z.M. Fresco, V.J. Murphy, J. Shoemaker, R. Archer, H. Jiang, Production of Adipic Acid and Derivatives from Carbohydrate-Containing Materials, US Pat. 2014/8669397 (2014), to Rennovia.

[25] G.M. Diamond, V. Murphy, T.R. Boussie, A. Hagemeyer, A.F. Volpe Jr., Application of high throughput experimentation to the production of commodity chemicals from renewable feedstocks, Modern Applications of High Throughput R \& D in Heterogeneous Catalysts, Bentham Science Publishers, 2014, pp. 288-309.

[26] P. Lanzafame, S. Perathoner, G. Centi, A vision for future biorefineries, in: F. Cavani, S. Albonetti, F. Basile, A. Gandini (Eds.), Chemicals and Fuels from BioBased Building Blocks, 1 Wiley VCH, 2016, pp. 497-518 Ch. 18.

[27] K.M. Draths, J.W. Frost, J. Am. Chem. Soc. 116 (1994) 399-400.

[28] W. Niu, K.M. Draths, J.W. Frost, Biotechnol. Prog. 18 (2002) 201-211.

[29] J.M. Thomas, R. Raja, B.F.G. Johnson, T.J. O'Connell, G. Sankar, T. Khimyak, Chem. Commun. 9 (2003) 1126-1127.

[30] D.R. Vardon, N.A. Rorrer, D. Salvachua, A.E. Settle, C.W. Johnson, M.J. Menart, N.S. Cleveland, P.N. Ciesielski, K.X. Steirer, J.R. Dorgan, G.T. Beckham, Green Chem. 18 (2016) 3397-3413.

[31] S. Scelfo, R. Pirone, N. Russo, Catal. Commun. 84 (2016) 98-102.

[32] J.G. DeVries, T. Buntara, P. Huat Phua I.V. Melian-Cabrera, H.J. Heeres, Preparation of caprolactone, caprolactam, 2,5-tetrahydrofuran-dimethanol, 1,6hexanediol or 1,2,6-hexanetriol from 5-hydroxymethyl-2-furfuraldehyde, WO Pat. 2011/149339 (2011), to NWO.

[33] T. Buntara, S. Noel, P.H. Phua, I. Melián-Cabrera, J.G. de Vries, H.J. Heeres, Angew. Chem. Int. Ed. 50 (2011) 7083-7087.

[34] T. Buntara, S. Noel, P.H. Phua, I. Melián-Cabrera, J.G. Vries, H.J. Heeres, Top. Catal. 55 (2012) 612-661.

[35] R. Alamillo, M. Tucker, M. Chia, Y. Pagan-Torres, J. Dumesic, Green Chem. 14 (2012) 1413-1419.

[36] K. Chen, S. Koso, T. Kubota, Y. Nakagawa, K. Tomishige, ChemCatChem 2 (2010) $547-555$.

[37] M. Chia, Y.J. Pagan-Torres, D. Hibbits, Q. Tan, H.N. Pham, A.K. Datye, M. Neurock, R.J. Davis, J.A. Dumesic, J. Am. Chem. Soc. 133 (2011) 12675-12689.

[38] S.P. Burt, K.J. Barnett, D.J. McClelland, P. Wolf, J.A. Dumesic, G.W. Huber, I. Hermans, Green Chem. 19 (2017) 1390-1398.

[39] A. Said, D. Da Silva Perez, N. Perret, C. Pinel, M. Besson, ChemCatChem 9 (2017) 2768-2783.

[40] A. Allgeier, N. Desilva, E. Korovessi, C. Menning, J.C. Ritter, S.K. Sengupta, Process for preparing 1,6-hexanediol, WO Pat. 2013/101980 (2013), to E.I. Du Pont de
Nemours and Company.

[41] S.H. Krishna, D.J. McClelland, Q.A. Rashke, J.A. Dumesic, G.W. Huber, Green Chem. 19 (2017) 1278-1285.

[42] M. Faber, Process for producing adipic acid from biomass, US Pat. 1983/4400468 (1983), to Hydrocarbon Research.

[43] M.S. Ide, R.J. Davis, J. Catal. 308 (2013) 50-59.

[44] M.S. Ide, D.D. Falcone, R.J. Davis, J. Catal. 311 (2014) 295-305.

[45] T. Wang, M.S. Ide, M.R. Nolan, R.J. Davis, B.H. Shanks, Energy Environ. Focus 5 (2016) 1-5.

[46] J. Xie, B. Huang, K. Yin, H.N. Pham, R.R. Unocic, A.K. Datye, R.J. Davis, ACS Catal. 6 (2016) 4206-4217.

[47] E.L. Dias, V.J. Murphy, J.A.W. Shoemaker, Process for production of adipic acid from 1,6-hexanediol, US Patent2013/0331606 (2013), to Rennovia.

[48] S.E. Davis, M.S. Ide, R.J. Davis, Green Chem. 15 (2013) 17-45.

[49] M. Besson, P. Gallezot, Catal. Today 57 (2000) 127-141.

[50] M. Besson, F. Lahmer, P. Gallezot, P. Fuertes, G. Fleche, J. Catal. 152 (1995) $116-121$.

[51] H. Ait Rass, N. Essayem, M. Besson, Green Chem. 15 (2013) 2240-2251.

[52] J. Xie, D.D. Falcone, R.J. Davis, J. Catal. 332 (2015) 38-50.

[53] A. Lolli, S. Albonetti, L. Utili, R. Amadori, F. Ospitali, C. Lucarelli, F. Cavani, Appl, Catal. A: Gen. 504 (2015) 408-419.

[54] C.L. Bianchi, P. Canton, N. Dimitratos, F. Porta, L. Prati, Catal. Today 102 (2005) 203-212.

[55] D.I. Enache, J.K. Edwards, P. Lanton, B. Solsona-Espriu, A.F. Carley, A.A. Herzing, M. Watanabe, C.J. Kiely, D.W. Knight, G.J. Hutchings, Science 311 (2006) 362-365.

[56] A. Villa, D. Wang, D. Su, G.M. Veith, L. Prati, Phys. Chem. Chem. Phys. 12 (2010) 2183-2189.

[57] W. Hou, N.A. Dehm, R.W.J. Scott, J. Catal. 253 (2008) 22-27.

[58] N. Dimitratos, J.A. Lopez-Sanchez, G.J. Hutchings, Chem. Sci. 3 (2012) 20-44.

[59] P. Korovchenko, C. Donze, P. Gallezot, M. Besson, Catal. Today 121 (2007) 13-21.

[60] M. Simões, S. Baranton, C. Coutanceau, Appl. Catal. B: Environ. 110 (2011) 40-49.

[61] A.-B. Crozon, M. Besson, P. Gallezot, New J. Chem. 22 (1998) 269-273.

[62] K. Heidkamp, M. Aytemir, K.-D. Vorlop, U. Prüesse, Catal. Sci. Technol. 3 (2013) 2984-2992.

[63] C. Louis, Catalysts 6 (2016) 110-136.

[64] E. Derrien, P. Marion, C. Pinel, M. Besson, Ind. Eng. Chem. Res. (2017), http://dx. doi.org/10.1021/acs.iecr.7b01571.

[65] K. Laaziri, S. Roorda, J. Baribeau, J. Non-Cryst. Solids 191 (1995) 193-199.

[66] H. Miura, K. Endo, R. Ogawa, T. Shishido, ACS Catal. 7 (2017) 1543-1553.

[67] T. Mallat, A. Baiker, Chem. Rev. 104 (2004) 3037-3058.

[68] A. Abad, P. Concepción, A. Corma, H. García, Angew. Chem. Int. Ed. 44 (2005) 4066-4069.

[69] L. Prati, P. Spontoni, A. Gaiassi, Top. Catal. 52 (2009) 288-296.

[70] A. Villa, D. Wang, N. Dimitratos, D. Su, V. Trevisan, L. Prati, Catal. Today 150 (2010) 8-15.

[71] N. Dimitratos, A. Villa, D. Wang, F. Porta, D. Su, L. Prati, J. Catal. 244 (2006) $113-121$.

[72] B.N. Zope, S.E. Davis, R.J. Davis, Top. Catal. 55 (2012) 24-32.

[73] T. Balcha, J.P. Strobl, C. Fowler, P. Dash, R.W.J. Scott, ACS Catal. 1 (2011) 425-436.

[74] X. Wan, C. Zhou, J. Vhen, W. Deng, Q. Zhang, Y. Yang, Y. Wang, ACS Catal. 4 (2014) 2175

[75] Y. Ryabenkova, P.J. Miedziak, D.W. Knight, S.H. Taylor, G.J. Hutchings, Tetrahedron 70 (2014) 6055-6058. 